\title{
Neurodegenerative and Fatiguing Illnesses, Infections and Mitochondrial Dysfunction: Use of Natural Supplements to Improve Mitochondrial Function.
}

\author{
Garth L. Nicolson ${ }^{1}$, Robert Settineri ${ }^{2}$ and Rita R. Ellithorpe ${ }^{3}$ \\ ${ }^{1}$ Department of Molecular Pathology, The Institute for Molecular Medicine, Huntington Beach, \\ CA 92647 USA; ${ }^{2}$ Sierra Research, Irvine, CA, 92606 USA; ${ }^{3}$ Tustin Longevity Center, Tustin, \\ California 92780, USA
}

Corresponding Author: Prof. Emeritus Garth L. Nicolson, Department of Molecular Pathology, Institute for Molecular Medicine, P. O. Box 9355, S. Laguna Beach, CA 92652

Submission date: November 08, 2013; Acceptance date: January 22, 2014; Publication date: January 25, 2014

\begin{abstract}
$\underline{\text { ABSTRACT }}$
Background: Many chronic diseases and illnesses are associated with one or more chronic infections, dysfunction of mitochondria and reduced production of ATP. This results in fatigue and other symptoms that occur in most if not all chronic conditions and diseases.
\end{abstract}

Methods: This is a review of the published literature on chronic infections in neurodegenerative diseases and fatiguing illnesses that are also typified by mitochondrial dysfunction. This contribution also reviews the use of natural supplements to enhance mitochondrial function and reduce the effects of chronic infections to improve overall function in various chronic illnesses.

Results: Mitochondrial function can be enhanced by the use of various natural supplements, notably Lipid Replacement Therapy (LRT) using glyerolphospholipids and other mitochondrial supplements. In various chronic illnesses that are characterized by the presence of chronic infections, such as intracellular bacteria (Mycoplasma, Borrelia, Chlamydia and other infections) and viruses, LRT has proven useful in multiple clinical trials. For example, in clinical studies on chronic fatigue syndrome, fibromyalgia syndrome and other chronic fatiguing illnesses where a large majority of patients have chronic infections, LRT significantly reduced fatigue by $35-43 \%$ in different clinical trials and increased mitochondrial function. In clinical trials on patients with multiple intracellular bacterial infections and intractable fatigue LRT plus other mitochondrial supplements significantly decreased fatigue and improved mood and cognition.

Conclusions: LRT formulations designed to improve mitochondrial function appear to be useful as non-toxic dietary supplements for reducing fatigue and restoring mitochondrial and other cellular membrane functions in patients with chronic illnesses and multiple chronic infections. 
Key words: Neurodegenerative and fatiguing illnesses, infections and mitochondrial dysfunction, ATP, Lipid Replacement Therapy (LRT)

\section{Background}

Patients with chronic neurodegenerative, neurobehavioral and fatiguing illnesses commonly test positive for systemic and central nervous system (CNS) bacterial and viral infections [1-3]. In addition, other chronic illnesses where neurological manifestations are routinely found, such as autoimmune diseases and other chronic illnesses and disorders, also show evidence of systemic bacterial and viral infections that could be important in disease inception, progression and/or enhancing the types and severities of signs and symptoms [2, 3].

Evidence of bacterial infections, such as Mycoplasma species, Chlamydia pneumoniae, Borrelia burgdorferi, among others, and viruses, such as human herpesvirus (HHV), cytomegalovirus (CMV), human herpes viruses (HHV) and other viral infections, have revealed high rates of infection in the illnesses listed above that were not found in control populations [13]. Although the specific roles of chronic infections in various diseases and their pathogeneses have not been carefully determined, the data suggest that chronic bacterial and/or viral infections are common features of essentially all progressive chronic diseases [1-3].

Another common finding in chronic illness patients is mitochondrial dysfunction, characterized by loss of efficiency in the electron transport chain, reductions in mitochondrial inner membrane trans-membrane potential and reductions in the synthesis of high-energy molecules such as ATP [4-6]. This is also a characteristic of aging, and it essentially occurs in all chronic diseases, including cancer [5-7].

This review will concentrate on commonly acquired mechanisms that affect mitochondrial function. To treat functional loss associated wtih chronic infections mitochondrial replacement strategies with natural supplements and combinations of natural supplements have been used, including vitamins, minerals, enzyme cofactors, antioxidants, metabolites, transporters, membrane-type phospholipids and other natural supplements in order to improve mitochondrial function.

\section{Introduction}

Chronic infections appear to be a common feature of various diseases, including neurodegenerative, psychiatric, neurobehavioral diseases and other conditions [1-3, 8]. Chronic infections are also associated with autoimmune diseases $[9,10]$ and fatiguing illnesses $[1,3,11]$. This will be discussed in various sections of this review. In addition, many chronic illnesses are directly caused by chronic infections, such as Lyme disease, brucellosis, babesiosis, and other infection-based chronic diseases [2, 12-14].

Chronic infections collectively result in induction of excess Reactive Oxygen Species (ROS) and Reactive Nitrogen Species (RNS) that damage cellular structures, especially mitochondrial membranes [15-17]. Mitochondria are especially sensitive to excess levels of ROS/RNS, and in chronic illnesses there is extensive damage to mitochondria in the form of membrane oxidation, damage to mitochondrial DNA (mtDNA) and loss of mitochondrial enzymatic function and inner mitochondrial membrane potential [6-8, 18-20]. In this review we will discuss the use of 
comprehensive approaches to restore mitochondrial function damaged by infections and other causes.

Patients with chronic illnesses (often caused by or exacerbated by chronic infections) are particularly difficult to treat using single modality approaches, and this is particularly true for patients who have multiple chronic infections [21, 22]. The multi-focal nature of chronic diseases and the fact that often treatments are given to suppress adverse signs and symptoms, rather than treat causes of the disease or its progression, have resulted in incomplete or ineffective treatments. On the other hand, even if the causes of chronic diseases are known, by the time therapeutic interventions are undertaken, it may be entirely too late to use approaches that might work on the disease at an early stage or if chronic infections were not also present. At the stage(s) of disease when patients usually seek medical care for their conditions, they usually have multiple problems, including chronic infections, and each of these problems usually requires complex therapeutic approaches. Their multiple chronic infections also cause additional cellular damage $[1,2,8]$.

Multiple alternations in mitochondrial membranes, proteins and mtDNA are thought to be the cause for mitochondrial dysfunction, and this damage can also accumulate over time [6, 23]. By the time patients seek care, they usually have multiple defects in their mitochondria, and thus there are no simple approaches that are effective in promoting functional recovery of their mitochondria. With this in mind, we have begun this review by discussing the evidence for chronic infections and mitochondrial dysfunction in selected chronic illnesses and diseases. Then we will discuss the role that various supplements play in restoring mitochondrial function, even in patients with multiple chronic infections that continue to degrade mitochondrial components. Finally we will discuss the role of combination supplements for restoring mitochondrial function in patients with chronic illnesses and multiple chronic infections.

\section{Neurodegenerative Diseases}

Neurodegenerative diseases, or chronic degenerative diseases of the central nervous system (CNS) that cause dementia, are mainly diseases of the elderly [1, 2]. On the other hand, neurobehavioral diseases are found mainly in young patients and include autism spectrum disorders (ASD), such as autism, attention deficit disorder, Asperger's syndrome and other disorders [24]. For the most part, the causes of these neurological diseases remain largely unknown but it is thought that multiple factors are involved in each disease $[1,2]$.

Neurodegenerative diseases are characterized by molecular and genetic changes in nerve cells that result in nerve cell dysfunction, degeneration and ultimately cell death, resulting in neurological signs and symptoms and eventually dementia [1,2]. In contrast, neurobehavioral diseases are related to fetal brain and early post-partum development but are less well characterized at the cellular level. Both of these disease types involve genetic and environmental factors [24, 25], and they also have multiple chronic infections [1-3, 26, 27]. Even less well characterized at the cellular and genetic level are the psychiatric disorders, such as schizophrenia, paranoia, bipolar disorders, depression and obsessive-compulsive disorders, but these diseases are also associated with the presence of chronic infections [3].

Genetic alternations have been found in neurodegenerative and neurobehavioral diseases, but the genetic changes as well as changes in gene expression that have been found are complex 
and usually not directly related to simple gene alterations, such as single mutations and deletions, that lead to single protein molecule alterations $[24,25,28]$. Importantly, mutations that affect mitochondrial function are known to be associated with neurodegenerative and neurobehavioral diseases [29, 30]. These include mutations in mtDNA as well as nuclear DNA [29]. In addition to chronic infections and genetic changes, environmental toxins, heavy metals, nutritional deficiencies, autoimmune immunological responses, vascular diseases, head trauma (and accumulation of fluid in the brain), changes in neurotransmitter concentrations, among other elements, are thought to be collectively involved in the pathogenesis of various neurodegenerative and neurobehavioral diseases [1,2, 24-31]. These important topics will not be discussed in detail in this review.

Chronic Infections are important factors in neurodegenerative and neurobehavioral diseases, and infectious agents may enter the brain within infected migratory macrophages. Alternatively, they can also gain access by direct penetration of the blood-brain-barrier or entry by intraneuronal transfer from peripheral nerves [32]. Cell wall-deficient bacteria, such as species of Mycoplasma, Chlamydia (Chlamydophila), Borrelia, Brucella, among others and various viruses are candidate brain infectious agents, because they are capable of CNS penetration and have been found routinely in neurodegenerative and neurobehavioral diseases [1-3, 26, 27, 32, 33]. Such infections are usually systemic and can affect immune systems and essentially any organ system, resulting in a variety of systemic signs and symptoms that are not limited to the CNS [10, 11, 26, 27, 32, 33].

\section{Amyotrophic lateral sclerosis (ALS)}

ALS is an adult-onset, progressive neurodegenerative disease of unknown etiology that affects both central and peripheral motor neurons where patients show gradual progressive weakness and paralysis of muscles due to destruction of upper motor neurons in the motor cortex and lower motor neurons in the brain stem and spinal cord [34, 35]. Eventually this results in death, usually by respiratory failure [35].

Chronic infections in ALS, such as the finding of enterovirus sequences in a majority of ALS spinal cord samples by polymerase chain reaction (PCR) [36], have attracted widespread attention. However, others have failed to detect enterovirus sequences in ALS spinal cord samples [37]. Using PCR methods systemic mycoplasmal infections have been found in a high percentage (83\%) of ALS patients [38]. For example, all of the tested Gulf War veterans diagnosed with ALS from three nations had systemic mycoplasmal infections [38]. In addition, a majority of ALS patients in Lyme endemic areas show immunological evidence of Borrelia infections [39], and some patients diagnosed with ALS were subsequently found to have neuroborreliosis infections [40]. Although high rates of infection may occur in certain regions, the overall rate of Borrelia infections in ALS is low (10\% or less) in North America [41]. MacDonald [42], however, observed a high incidence of spirochetal forms in the brain tissues of ALS patients and in patients with other neurodegenerative diseases, suggesting that the presence of chronic bacterial infections in the CNS of neurodegenerative diseases patients is much more common than previously assumed.

ALS patients also show evidence of other infections. These include: human herpes virus-6 (HHV-6), Chlamydia pneumoniae, cyanobacteria and other infections [43-45]. Chronic 
infections plus other defects (accumulation of glutamate causing excitotoxicity, deficiency of nerve growth factor, autoimmune reactions against motor neurons and dysfunction of mitochondrial superoxide dismutase) have been proposed to be important in ALS pathogenesis [review: 2].

Mitochondrial dysfunction is a common feature of ALS and animal models of ALS [46, 47]. Evidence from patients with sporadic and familial ALS and from ALS models based on the over-expression of mutant SOD1 found in a small subset of patients, clearly point to mitochondrial damage as a relevant facet of this neurodegenerative condition [46]. In addition to mutations in superoxide dismutase genes, some ALS patients present with mutations in mitochondrial transport genes and misfolding in inclusion proteins, ubiquilin-2 and other mitochondrial associated proteins [review: 47]. Dysfunction in several other cellular mechanisms, including mitophagy, oxidative stress, lipid peroxidation and cholesterol esterification, protein and neurofilament aggregation, impaired axonal transport, among other changes in ALS patients have been reviewed recently [47, 48].

\section{Multiple Sclerosis (MS)}

The most common demyelinating neurological disease is MS [49]. MS can occur in all age groups as a cyclic (relapsing-remitting) or a progressive disease that continues progressing without remitting [49]. Inflammation and the presence of autoimmune antibodies against myelin and other nerve cell antigens are thought to cause myelin sheath breakdown, resulting in decrease or loss of electrical impulses along nerve fibers [49, 50]. In the MS patients with progressive neurological symptoms damage occurs additionally by the deposition of plaques on nerve cells to the point where nerve cell death occurs. Importantly, breakdown of the bloodbrain barrier in the CNS of MS patients is associated with local inflammation caused by activated glial cells $[49,50]$. The combination of demyelinization, plaque damage and bloodbrain barrier disruption causes multiple, variable symptoms, but they usually include impaired vision, alterations in motor, sensory and coordination nerve systems along with cognitive dysfunction [50].

MS is a disease in which environmental, genetic and epigenetic factors determine the risk of developing MS, its progression and responsiveness to treatment [51, 52]. Just as in ALS, there are multiple genetic components in MS [51,53]. Although it has been established that there is a genetic basis to MS susceptibility, epidemiological and twin studies suggest that MS is basically an acquired disease with some genetic and environmental components [54].

The molecular mechanisms through which environmental signals are translated into changes in gene expression include: DNA methylation, post-translational modification of nucleosomal histones, and non-coding RNAs. These mechanisms are regulated by families of specialized enzymes that are tissue-selective and cell-type specific [54].

Chronic infections have been linked to the pathophysiology of MS [55, 56]. For example, MS patients show immunological and cytokine elevations consistent with chronic infections [57, 58]. An infectious basis for MS has been under examination for some time, and patients have been tested for various viral and bacterial infections $[1,3,53,55,56]$.

One of the most consistent findings in MS patients has been the presence of C. pneumoniae antibodies and DNA in their cerebrospinal fluid [59-61]. By examining relapsing-remitting and 
progressive MS patients for the presence of $C$. pneumoniae in cerebrospinal fluid by culture, PCR and immunoglobulin reactivity Sriram et al. [60] were able to identify C. pneumoniae in $64 \%$ of MS cerebrospinal fluid versus $11 \%$ of patients with other neurological diseases. They also found high rates of PCR-positive MOMP gene (97\%) in MS- patients (versus 18\% in other neurological diseases), and this correlated with a high rate of patients being serology-positive (86\%) for Chlamydia antigens by ELISA and Western blot analysis [60]. MS patients examined for oligoclonal antibodies against $C$. pneumoniae revealed that $82 \%$ of MS patients were positive compared to none of the control non-MS neurological patients [61]. Similarly, C. pneumoniae RNA and DNA transcripts were found in mononuclear cells and cerebrospinal fluids of $64.2 \%$ of MS patients but in only 3 controls [62].

The brain tissues of MS and non-MS neurological patients have also been examined for $C$. pneumoniae antigens [63]. Using immunohistochemistry to find $C$. pneumoniae antigens in formalin-fixed brain tissue Sriram et al. [63] found that in a subset of MS patients (35\%) Chlamydial antigens were localized to ependymal surfaces and pariventricular regions. Positive reactions were not found in brain tissue samples from other neurological diseases. PCR amplification of $C$. pneumoniae genes was accomplished in $63 \%$ of brain tissue samples from MS patients but none in frozen brain tissues from other neurological diseases. In addition, using immuno-electron microscopy the sediment from cerebrospinal fluid was examined for Chlamydial antigens [63]. Sriram et al. [63] found that the electron dense bodies resembling bacterial structures that were positive by immuno-electron microscopy correlated with tissue PCR-positive MS cases ( $91 \%$ positive using both methods).

Using different nested PCR methods to examine additional $C$. pneumoniae gene sequences in the cerebrospinal fluid of $72 \mathrm{MS}$ patients Contini et al. [64] were able to match these results to MS-associated lesions seen by MRI. Grimaldi et al. also used MRI to link the presence of $C$. pneumoniae infection with abnormal MRI results and found linkage in 21\% in MS patients [65]. The MS patients with $C$. pneumoniae infections were also the MS patients with more progressive disease. Indeed, higher rates of $C$. pneumoniae transcription were found in the cerebrospinal fluid of 84 patients with the more progressive form of MS [66]. These studies strongly support the presence of $C$. pneumoniae in the brains of MS patients with progressive disease [67, 68].

Not all researchers have found C. pneumoniae or other bacteria in the brains of MS patients $[69,70]$. For example, Hammerschlag et al. used nested PCR and culture to examine frozen brain samples from MS patients but could not find any evidence for $C$. pneumoniae gene sequences [71]. Thus the evidence linking $C$. pneumoniae infection with MS is not universally accepted, and other genetic changes may be necessary to complete the link between such infections and the etiology of MS [72].

Multiple infections in MS patients may complicate the evidence linking MS with specific chronic infections. Thus other infections similar to $C$. pneumoniae could be involved rather than just one specific infection [1]. In addition to $C$. pneumoniae, MS patients could also have Mycoplasma species, B. burgdorferi and other bacterial infections as well as viral infections [73]. When multiple infections are considered, it is likely that $>90 \%$ of MS patients have obligate intracellular bacterial infections.

Various viruses have also been found in MS patients. For example, HHV-6 has been found at higher frequencies in MS patients, but this virus has also been found at lower incidence in 
control samples [74]. PCR was used to examine postmortem brain tissue and controls for the presence of various neurotrophic viruses [74]. These studies revealed that $57 \%$ of MS cases and $43 \%$ of non-MS neurological disease controls contain sequences for HHV-6, whereas 37\%, 28\%, and $43 \%$, respectively, contained sequences for herpes simplex virus (HSV)-1 and -2 and varicella zoster virus. Although impressive, the data did not achieve statistical significance. They also found that $32 \%$ of the MS active plaques and $17 \%$ of the inactive plaque areas were positive for HHV-6 [74].

Using sequence difference analysis Challoner et al. searched for pathogens in MS brain specimens and found that $>70 \%$ of MS patients were positive for infection-associated sequences [76]. They also used immunocytochemistry and found positive staining around MS plaques more frequently than around surrounding white matter. Additionally, HHV-6 DNA was found in peripheral leukocytes in the systemic circulation of MS patients [77] but not in every study [78].

Examination of the literature strongly suggests an infectious process in MS [1, 55, 56, 79, 80]. In most studies the more progressive forms of MS rather than the relapsing-remitting forms of MS were associated with chronic infections. Thus chronic infections may play a role in progression of MS. If infections like C. pneumoniae and Mycoplasma species are important in MS, then antibiotics effective against these infections should improve clinical status [1]. This has, in fact, been seen in most but not in all MS patients [81]. As in other neurodegenerative diseases, multiple factors appear to be involved in the pathogenesis of MS [1, 49, 55, 56, 82].

One of the factors in MS appears to be mitochondrial dysfunction due to oxidative injury $[83,84]$. Broadwater et al. have identified several MS-related damaged mitochondrial proteins that are involved in respiration, including cytochrome c oxidase subunit 5b, an isozyme of creatine kinase, and hemoglobin $\square$ eta chain [85]. One of the lesions in MS mitochondria appears to be damage to the permeability transition pore (PTP) by excess reactive oxygen species (ROS) [86]. This critical structure is central to mitochondrial dysfunction by allowing ion dysregulation within neural cells that drives neurodegeneration by allowing the PTP to change the ion gradients inside mitochondria, lowering inner membrane trans-membrane potential (thus reducing oxidative phosphorylation [87]), promoting matrix expansion leading to release of cytochrome $\mathrm{c}$ and initiating cell death programs [86]. In addition, the energy and calcium balance in neurons plays an important role in maintaining a healthy myelin sheath, and a hallmark of MS is axon demyelation due to mitochondrial dysfunction [83], which drives an inflammatory response characteristic of MS progression [88].

\section{Alzheimer's disease (AD)}

$\mathrm{AD}$ is characterized by distinct pathological changes in brain cells and tissues [1,2]. Among the most notable are the appearance of plaques and tangles of neurofibrils in brain nerve cells that affect synapses and nerve-nerve cell communication. These alterations involve the deposition of altered amyloid proteins $[89,90]$. Although the origins of AD are not known for certain, the formation of the amyloid plaques and neurofiber tangles found in $\mathrm{AD}$ may be due to genetic defects and resulting changes in the structure of beta amyloid proteins, which may be caused by chemicals or other toxic events, inflammatory responses, excess oxidative stress and increases in ROS, loss of nerve trophic factors and reductions in nerve cell transmission [89-92]. 
Infections are potentially important in the AD disease process [93, 94]. One pathogen that has attracted considerable attention because of its neurotropism is $C$. pneumoniae $[95,96]$. This intracellular bacterium has been found at high incidence in the brains of AD patients by PCR and immunohistochemistry [96]. C. pneumoniae has also been found localized in nerve cells in close proximity to neurofibrillary tangles, a characteristic of $\mathrm{AD}[96,97]$.

C. pneumoniae can invade endothelial cells and promote the transmigration of monocytes through human brain endothelial cells into the brain parenchyma [98]. C. pneumoniae has been found in the brains of most AD patients [95], and it has been cultured from the brain tissue of AD patients [99]. Immunohistological detection of C. pneumoniae was observed inside and outside cells in the frontal and temporal cortices of AD brains [100]. Indeed, in experiments with mice injection of C. pneumoniae stimulated brain beta amyloid plaque formation [101]. The data are compelling, but some investigators have not been able to duplicate the findings on infections in $\mathrm{AD}[102]$.

In addition to C. pneumoniae investigators have found other infections in AD patients, such as B. burgdorferi $[103,104]$. Using serology, culture, Western blot and immunofluorenscence methods this infection has been examined in AD patients (with or without a diagnosis of Lyme disease) and found to be present $[104,105]$. The presence of intracellular infections like $B$. burgdorferi in $\mathrm{AD}$ patients has been proposed to be a primary event in the formation of AD beta amyloid plaques, which are thought to occur by the formation of "congophilic cores" that attract beta amyloid materials [106]. In fact, exposure of glial and neuronal cells in vitro to Borrelia burgdorferi spirochetes and to the inflammatory bacterial lipopolysaccharide LPS caused morphological changes analogous to those found in deposits in AD brains [107]. Also detected were increases in beta amyloid precursor protein and hyperphosphorylated tau protein characteristic of AD [107]. Several reports indicate that AD nerve cells are often positive for $B$. burgdorferi, indicating that this intracellular bacteria could be important in the pathogenesis of AD [103-106, 108]. However, there are reports that could not find evidence for the presence of Borrelia in AD brain tissue [109].

Miklossy has reviewed the data indicating that chronic infections, including B. burgdorferi, are commonly found in $\mathrm{AD}$ patients and has concluded that intracellular bacteria contain amyloidogenic proteins that can induce amyloid beta deposition and tau phosphorylation [110, 111]. In addition, specific bacterial ligands and bacterial and viral DNA and RNA increase the expression of proinflammatory molecules that activate the innate and adaptive immune systems. Evasion of brain pathogens from destruction by the host immune system can result in persistent infection, chronic inflammation, neuronal destruction and beta amyloid deposition [111].

The hypothesis that intracellular microorganisms or their protein products can induce beta amyloid protein and then provide "nucleation sites" for the attraction of beta amyloid materials is attractive [111], but other factors, including the induction of reactive oxygen species, lipid peroxidation and the breakdown of the lysosomal membranes releasing lysosomal hydrolases, are also thought to be important in beta amyloid deposition [108]. An infectious basis in AD pathogenesis is attractive; however, although some negative reports imply that infections like $B$. burgdorferi are not essential in AD pathogenesis [109]. On the other hand, other intracellular bacterial infections (Mycoplasma, Chlamyda, Helicobacter etc.) have been found in AD patients and could be present in those patients who are negative for Borrelia infections [111-113]. It has 
been proposed that chronic infections may be important cofactors in $\mathrm{AD}$ and contribute to the pathogenic process [113].

Viral infections may also play a role in $\mathrm{AD}$ pathogenesis. Herpes virus infections, especially HSV-1, have been found in AD patients [114, 115]. Previously it was determined that HSV-1 but not a related neurotrophic virus (varicella zoster virus) was present more often in AD brains, and this could be linked to patients who have the AD risk factor ApoE e4 allele [116, 117]. Similar to bacterial proteins, HSV-1 proteins may also be involved in the abnormal aggregation of beta amyloid fragments within the $\mathrm{AD}$ brain, but in this case by reducing the amount of full-length beta amyloid precursor protein and increasing the amounts of their fragments [118]. HSV-1 infection of glial and neuronal cells resulted in a dramatic increase in the intracellular levels of beta amyloid forms, whereas the levels of native beta amyloid precursor protein decreased [119]. This has been found in mice infected with HSV-1, indicating that HSV-1 is probably involved directly in the development of senile-associated plaques. Other herpes viruses, such as HHV-6, have also been found in AD patients, but it is thought that this virus is not directly involved in AD pathogenesis. Another virus that has been implicated in AD is cytomegalovirus [120]. A high proportion of brains from vascular dementia patients show evidence of both HSV-1 and cytomegalovirus [120].

Mitochondrial dysfunction may be an early event in the pathogenesis of AD [121-123]. AD patients show impairments in mitochondrial function that start early in process of neurodegeneration [121, 123]. Mutations in the AbetaPP and tau genes induce oxidative stress and mitochondrial dysfunction leading eventually to apoptotic cell death [124]. Indeed, transgenic mouse models of $\mathrm{AD}$ point to impairments in oxidative phosphorylation as an important aspect of $\mathrm{AD}$ pathogenesis [125]. The oxidative stress is thought to cause protein alterations that have synergistic effects on mitochondria, leading to synaptic dysfunction and apoptotic cell death [124].

\section{Parkinson's Disease (PD)}

PD is characterized by akinesia, muscular rigidity and tremor. In addition, autonomic dysfunction, olfactory disturbances, depression, sensory and sleep disturbances and frequently dementia characterize this disease [126]. The pathology indicates a progressive loss of the dopamine neurons of the substantia nigra together with the presence of Lewy bodies and $\square$ lphasynuclein. Extensive brain degeneration also occurs in PD [127]. Inclusion bodies and protein aggregations or defects in their degradation characteristically are characteristic of PD, but their role in PD pathogenesis is unclear [127, 128]. Available evidence suggests a relationship between PD and specific genetic changes, such as changes in the genes in mitochondria, those affecting protein degradation, organelle trafficking and vesicular fusion, and in proteins involved in oxidative stress or antioxidant function [129. 130]. Inflammation has also been associated with PD [131].

PD has been proposed to be due to neurotoxic events in genetically susceptible individuals that are especially sensitive to neuro-oxidative damage [132]. Multiple environmental factors and genetic background are also statistically related risk factors for PD [133]. The mitochondria in neuromelanin-containing dopaminergic neurons of the substantia nigra are the targets for oxidative damage [128, 133, 134], and early life exposures are also important [135]. For 
example, early life exposure to brain injury, chemicals and/or infections may initiate a cyclic inflammatory process involving oxidative damage, excitotoxicity, mitochondrial dysfunction and altered proteolysis that later in life results in neuron death in the substantia nigra [136, 137].

Chronic infections have been proposed as important in PD pathogenesis [136, 137]. In fact, regression analysis of a case-control study on infections in PD patients clearly showed that infectious processes are an important risk factor in PD [138]. One infection found in PD that has aroused considerable interest is the presence of chronic gastrointestinal Helicobacter pylori infections [139]. Treatment of this infection in PD patients offered relief from late stage cachexia [140]. Helicobacter pylori-infected PD patients also showed reduced L-dopa absorption and increased clinical disability [141], and in antimicrobial-treated PD patients there was increased L-dopa absorption and decreased clinical disability [142]. Although H. pylori may not be directly involved in the pathogenesis of PD, its systemic presence has been proposed to affect the progression and treatment of PD [141].

PD patients' chronic infections have been linked to autoimmunity and inflammation [143145], and the role of neuro-inflammatory and oxidative processes in nigral degeneration has gained increasing attention [145, 146]. Moreover, experimental models of PD have been developed using viral or bacterial infections to initiate the pathogenic process $[147,148]$. In examining PD patients various infections have been found, especially bacterial and viral infections [144, 149]. For example, spirochetes have also been found in the brain Lewy bodies of Lyme-associated PD patients [150]. Other infections, such as viral encephalitis [151], cornavirus [152], Mycoplasma pneumoniae [153], AIDS-associated infections of the basal ganglia [154], HIV [155], among other infections, have been found in PD patients [144, 149, 155]. Additional research will be necessary to establish whether a causal link exists between PD and chronic infections $[143,155,156]$.

A common link between oxidative stress, mitochondrial dysfunction and PD exists [157, 158]. Although the underlying mechanisms for selective dopaminergic nerve degeneration in PD are not completely known, the increase in ROS in Parkinson's substantia nigra neurons results in increased DNA mutation, especially in mtDNA, reduced efficiency of the electron transport chain, and changes in protein aggregation and lipid oxidation that contribute to mitochondrial destruction (mitophagy) and neurodegeneration [132, 145, 156-158]. Mutations in genes that protect neural cells from oxidative damage-mediated mitochondrial dysfunction, such as tensin (PTEN) homologue-induced kinase-1 (PINK1), are known to be associated with recessively inherited PD, and this also points to mitochondrial damage as an underlying defect in PD [159]. PINK1 is involved in mitochondrial quality control, and under steady state conditions PINK1 is rapidly and constitutively degraded in a mitochondrial membrane potential-dependent manner [160]. Loss of mitochondrial inner membrane potential stabilizes PINK1 mitochondrial accumulation and stimulates the initiation of autophagic degradation and removal of damaged mitochondria (mitophagy), but mutations in PINK1 inhibit this process [161]. This implicates loss of mitochondrial integrity and mitophagy in the pathogenesis of PD.

\section{Neurobehavioral Diseases}

Autism spectrum disorders (ASD) 
ASD includes autism, Asperger's syndrome, among other disorders. These diseases affect primarily young patients who generally suffer from an inability to properly communicate, form relationships with others and respond appropriately to their environment. ASD patients do not all share the same signs and symptoms but tend to have in common certain social, communication, motor and sensory problems (non-compliance, hyperactivity, sensory defensiveness, self-injury, among others) that affect their behavior. They can display repetitive actions and develop troublesome fixations with specific objects, and they are often painfully sensitive to certain sounds, tastes and smells [162, 163].

Multiple factors appear to be involved in ASD, including genetic factors, environmental exposures, such as heavy metals and chemicals and biological exposures, which are probably different in each patient [27, 28, 164-169]. ASD patients appear to have similarities in genetic defects and environmental exposures that have been proposed to play interactive roles that are probably important in patient morbidity or in illness progression [170, 171].

Chronic infections appear to be an important element in the development of ASD [2, 26, 27, 168, 169]. In ASD patients more than 50 different bacterial, viral and fungal infections have been documented [27]. A few of these occur at high incident rates and may be more important than others in causing ASD symptoms [2, 169]. ASD patients also present with a number of nonspecific chronic signs and symptoms that suggest infections, such as fatigue, headaches, gastrointestinal and vision problems as well as intermittent low-grade fevers and other signs and symptoms [169, 172]. Increased titers to various viruses as well as bacterial and fungal infections have been commonly seen in ASD patients [27, 169, 172-174].

Infections along with environmental exposures to chemicals and heavy metals is controversial but in some cases may be important in the development of ASD in genetically susceptible children [27, 28,166-174]. The relationship between ASD and heavy metals is controveral but could be linked to the multiple vaccines given during pre-school years [166, 167]. ASD often developes only after multiple childhood immunizations, and the sharp increase in Autism may be linked to vaccines after they came into widespread use [167]. Many of these vaccines contain mercury and other toxic preservatives, and some may also contain contaminating bacteria, as found in $6 \%$ of veterinary vaccines [175]. ASD is also related to environmental infections, such as Lyme Borrelia and associated co-infections [21, 27, 169, 174].

An interesting study on the transmission of infections and subsequent ASD has come from the families of veterans of the Gulf War [176, 177]. After veterans with Gulf War Illness returned to the home, their children subsequently became symptomatic, and these children were often diagnosed with ASD [178]. Symptomatic children with ASD were infected with the same Mycoplasma species, M. fermentans, that was found in the veterans and their symptomatic family members, and this was not seen in aged-matched control subjects or in military families without GWI. In these families some non-symptomatic family members did have mycoplasmal infections $(\sim 10 \%)$, but this was not significantly different from the incidence of mycoplasmal infections in healthy control subjects $[177,178]$.

Non-military families were also examined for systemic mycoplasmal infections [26]. In the ASD cases a majority were positive for mycoplasmal infections. In contrast to the children from military families who for the most part had only $M$. fermentans, the civilian children tested positive for a variety of Mycoplasma species [26]. For example, a large subset (>58\%) of ASD 
patients showed evidence of Mycoplasma infections compared to age-matched control subjects (Odds Ratio=13.8, p<0.001). ASD patients were also examined for C. pneumoniae $(8.3 \%$ positive, Odds Ratio=5.6, p<0.01) and HHV-6 (29.2\% positive, Odds Ratio=4.5, p<0.01). The results indicated that a large subset of ASD patients have bacterial and/or viral infections (Odds Ratio=16.5, $\mathrm{p}<0.001$ ) [26].

In addition to Mycoplasma infections, many ASD patients have B. burgdorferi infections [179]. Various studies revealed that 22-30\% of ASD patients have Borrelia infections [169]. The incidence of Borrelia infections in ASD patients may be related to Lyme disease distribution, and other Lyme-associated infections, such as Bartonella, Babesia, Ehrlichia, may also be present in ASD patients [169].

Mitochondrial dysfunction is a common finding in ASD [180, 181]. Many mitochondrial biomarkers were significantly different between ASD patients and controls, and some markers correlated with ASD signs and symptoms severity [181]. Because of the similarities in symptoms, mitochondrial dysfunction in ASD patients may be related to non-ASD mitochondrial disease [181]. In addition, there was also an association between ASD and immune dysregulation and inflammation, oxidative stress, and toxicant exposures [182]. Palmieri and Persico have proposed that mitochondrial dysfunction in ASD is a down-stream affect, since it cannot be directly linked to many genetic or genomic defects found in ASD patients. Thus mitochondrial dysfunction in ASD may be due to the consequences of dysreactive immunity or altered calcium signaling [183].

\section{Fatiguing Illnesses}

Fatigue is usually understood as a subjective loss of energy and inability to perform even simple tasks without exertion. It is the most common complaint of patients seeking general medical care $[184,185]$. Fatigue occurs naturally during aging, and it is also an important secondary condition in many clinical illnesses, including respiratory, coronary, musculoskeletal, and bowel conditions as well as infections [184-186].

\section{Chronic Fatigue Syndrome (CFS)}

Chronic fatigue lasting more than 6 months that is not reversed by normal sleep along with other signs/symptoms (including neurophysiological) usually indicates CFS [187, 188]. CFS patients also display immune abnormalities, inflammation, autonomic dysfunction and impaired functioning of the hypothalamic-pituitary-adrenal axis [189-191]. This results in alternations in immune cells, such as natural killer cells, and release of pro-inflammatory cytokines [191-195].

Most CFS patients have multiple chronic bacterial and viral infections [196-200]. A common finding was systemic Mycoplasma species [197, 200]. For example, when patients were examined for evidence of any multiple, systemic bacterial and viral infections, the odds ratio for this was found to be 18 (CI 95\% 8.5-37.9, p<0.001) [197]. In addition to Mycoplasma species $(\mathrm{OR}=13.8, \mathrm{CI} 95 \%$ 5.8-32.9, $\mathrm{p}<0.001)$, co-infections with $C$. pneumoniae $(\mathrm{OR}=8.6, \mathrm{CI}$ 95\% 1.0-71.1, $\mathrm{p}<0.01)$ and HHV-6 (OR=4.5, CI 95\% 2.0-10.2, p<0.001) were also found [197]. The presence of these infections was also related to the number and severity of signs and symptoms [201]. Similarly, Vojdani et al. also found Mycoplasma species in a majority of CFS/ME patients [200], but this has not been seen in all studies [202]. Regional differences may 
be important, because when European CFS patients were examined for various Mycoplasma species, the most common species found was M. hominis [203], whereas in North America the most common species found was M. pneumoniae [197, 201].

CFS patients are also often found to be infected with B. burgdorferi [204], C. pneumoniae [197, 201, 205], cytomegalovirus [206], B19 parvovirus [207] and HHV-6 [197, 201, 208]. However, not all studies on infections in CFS patients have been accurate. A recent finding of a retrovirus (XMRV) in CFS patients has been proven to be an artifact [209].

As with other diseases that show high rates of chronic infections, CFS patients are also dysfunctional in their mitochondria [210, 211]. Studies have shown deficiencies in ATP production [210, 211] and reduced mitochondrial inner membrane potential [212] in white blood cells from CFS patients. Myhill et al. have proposed that CFS patients have basically two types of mitochondrial impairments: substrate or co-factor deficiencies or defects caused by exogenous or endogenous mitochondrial toxic factors [213]. Intracellular infections are likely the most common cause of the latter type of mitochondrial dysfunction.

\section{Fibromyalgia (FM)}

FM has many signs and symptoms in common with CFS, such as debilitating fatigue, mood and cognitive changes and sleep disturbances, but FM patients also present with widespread pain and abnormal pain processing [214, 215]. Among the risk factors for FM include genetic predisposition, obesity, allergies, toxins, autoimmune responses, physical trauma and chronic infections [215, 216]. Up to 70\% of FM patients are also diagnosed with CFS [217].

As with CFS, a high incidence of chronic bacterial and viral infections have been found in FM patients [2, 215]. Among the most commonly found infections are due to intracellular bacteria, such as Mycoplasma, Chlamydia, Brucella and Borrelia (reviewed in [215]). Similarly, viral infections have also been noted, such as cytomegalovirus, enteroviruses and HHV-6 (reviewed in [215]). These infections are often found at the same or higher incidence rates as those found in CFS patients.

Autoantibodies are routinely found in FM patients. One study reported thyroid autoantibodies in $41 \%$ of FM patients versus $15 \%$ of controls [218], and another report indicated $34.4 \%$ of FM patients were positive versus $18.8 \%$ in controls $(p=0.025)$ [219]. Autoantibodies to serotonin were also identified in $74 \%$ of 50 patients with FM compared with $6 \%$ of 32 controls [220].

As with CFS, FM patients show dysfunctional mitochondria [221, 222]. Excess oxidative stress was indicated by lipid peroxidation in blood mononuclear cells and plasma from FM patients [222]. In addition, reduced inner mitochondrial membrane potential initiating mitophagy and reductions in functional mitochondria were also found, suggesting that oxidative stress and increased mitophagy may play a role in the pathophysiology of FM [222]. Similar to CFS patients, FM patients also show reduced production of ATP but there were also some differences between CFS and FM patients. In FM patients lower levels of citrate synthase and other enzymes and lower amounts of mtDNA were found compared to CFS patients [223]. 


\section{Consequences of Mitochondrial Dysfunction}

Mitochondrial dysfunction arises from an inadequate number of mitochondria within cells, an inability to provide necessary substrates and cofactors to mitochondria, and dysfunction in their electron transport or ATP synthesis machinery. The number and functional status of mitochondria in a cell can be changed by the fusion of partially dysfunctional mitochondria and mixing of undamaged components to improve overall function (mitophagy), the generation of entirely new mitochondria (fission), and the removal and complete degradation of dysfunctional mitochondria (autophagy) [224]. These events are controlled by complex cellular processes that sense the deterioration of mitochondria, such as the loss of inner mitochondrial membrane potential or the activation of certain transcription pathways [225].

The ability of mitochondria to produce high-energy molecules like ATP is directly related to the ability of the electron transport chain to convert the energy of metabolites to transfer electrons to the electron transport chain from NADH and eventually to molecular oxygen while pumping protons from the mitochondrial matrix across the inner mitochondrial membrane to the intermembrane space [225]. This creates a transmembrane proton gradient $(\Delta \mathrm{p})$ and electrochemical gradient $\left(\Delta \square_{\mathrm{m}}\right)$ across the mitochondrial inner membrane that is used by ATP synthase to generate ATP [226].

As a consequence of the electron transport process highly reactive free radicals, such as Reactive Oxygen Species (ROS), are produced as a byproduct of oxidative phosphorylation. The main cellular sources of ROS and related Reactive Nitrogen Species (RNS) are mitochondria, and when produced in excess over cellular antioxidant systems these free radicals can damage cellular lipids, proteins and DNA [227-229]. There are cellular mechanisms to neutralize excess ROS/RNS, such as dismutase enzymes and antioxidants [230]. Another mechanism to control the amount of excess ROS is by a controlled leak of protons back across the inner mitochondrial membrane via uncoupling proteins that allow protons to flow against the proton gradient [226, 231].

Excess oxygen consumption, controlled mitochondrial proton leak and resulting ROS production can result in inappropriate damage to mitochondrial membrane lipids [228, 232], such as the very ROS/RNS-sensitive inner mitochondrial phospholipid cardiolipin [232]. Oxidative damage of inner mitochondrial membrane cardiolipin and other membrane phospholipids can result in increased proton and ion leakage across the inner membrane and partial loss of the electrochemical gradient. Cardiolipin is an important component of the electron transport chain, providing stability for the cytochrome/enzyme complexes in the inner mitochondrial membrane [232, 233]. If damaged by ROS/RNS, oxidized cardiolipin results in loss of electron transport function [233].

Antioxidant defenses usually maintain ROS/RNS levels at concentrations that do not result in oxidation of cellular molecules or stimulate adverse events like carcinogenesis [234, 235]. Endogenous cellular antioxidant defenses are essentual for protecting cellular molecules from oxidative damage and are mediated by proteins, such as glutathione peroxidase, catalase and superoxide dismutase, among others [236, 237]. There are also low molecular weight dietary antioxidants that can modify anti-oxidant oxidant balance [238-240]. Some of these dietary antioxidants have been used as natural preventive agents to shift the excess concentrations of 
oxidative molecules down to physiological levels that can be maintained by endogenous cellular antioxidant systems [241].

\section{Supplements for Fatigue and and Mitochondrial Dysfunction}

Although mild fatigue can be related to psychological disturbances, moderate to severe fatigue is almost always related to loss of mitochondrial function and diminished production of ATP [211, 212]. A number of natural supplements have been used to treat non-psychological fatigue and mitochondrial dysfunction [6, 242-244]. These include supplements containing vitamins, minerals, antioxidants, metabolites, enzyme inhibitors and cofactors, mitochondrial transporters, herbs and membrane phospholipids (Table 1) [6, 243]. Although several natural supplements have been used to reduce fatigue and improve mitochondrial function, few are considered effective [245]. Among the most useful supplements are the following:

Table 1. Relative Incidence of Some Infectious Agents in Patients with Chronic Disease*

\section{ALS MS AD PD ASD CSF FM}

\begin{tabular}{|c|c|c|c|c|c|c|c|}
\hline Borrelia spp & ++ & ++ & ++ & + & ++ & ++ & ++ \\
\hline Chlamyda spp. & + & ++++ & +++ & ++ & ++ & ++ & ++ \\
\hline Mycoplasma spp. & +++++ & +++ & ++ & ++ & +++++ & +++++ & +++++ \\
\hline Brucella spp. & + & & & & +++ & ++ & ++ \\
\hline Cytomegalovirus & & ++ & + & & ++ & + & + \\
\hline $\mathrm{HSV}-1$ & + & +++ & +++ & & ++ & & \\
\hline HSV-2 & & + & & & + & & \\
\hline HHV-6 & ++ & +++ & ++ & & +++ & +++ & +++ \\
\hline Heliobacter spp. & & & ++ & +++ & + & + & + \\
\hline Other virus/bacteria & +++ & +++ & ++ & ++ & +++ & ++ & +++ \\
\hline
\end{tabular}

*Abbreviations: AD, Alzheimer's disease; ALS, amyotrophic lateral sclerosis; ASD, autism spectrum disorders; CFS, chronic fatigue syndrome; FM, fibromyalgia; HSV, herpes simplex virus; HHV, human herpes virus; MS, multiple sclerosis;

PD, Parkinson's disease

Incidence (above controls): -, 0-1\%; +, 1-5\%; ++, 6-15\%; +++, 16-25\%; ++++, 26-50\%; +++++, 51-90\%

\section{L-Carnitine (LC)}

LC (3-hydroxy-4-N-trimethylaminobutyrate) is a naturally occurring fatty acid transporter found in all species of mammals that is directly involved in the transport of fatty acids into the mitochondrial matrix for subsequent $\beta$-oxidation [246, 247]. It also functions in the removal of excess fatty acyl groups from the body and in the modulation of intracellular Coenzyme A (CoA) homeostatasis [246, 247]. Due to its importance in fatty acid oxidation and CoA and acyl-CoA homeostatasis, LC is usually maintained within relatively narrow concentration limits. It is an important dietary supplement for maintaining optimal LC concentration within cells [246]. Thus LC deficiency disorders are associated with reduced mitochondrial function, insulin resistance and coronary artery disease [248, 249]. 
The importance of LC in mitochondrial health has spurred the use of LC supplements to potentially improve mitochondrial function and physical performance [250]. The justification is that increased reliance on fat as the principle substrate for energy production during extreme exercise should reduce the need for carbohydrates and delay the depletion of carbohydrate stores. This should increase overall energy production and reduce exercise-induced fatigue. Increased reliance on lipids requires increased levels of LC to transport fatty acids into mitochondria. However, increasing intake of oral LC, even for a few weeks prior to extreme exercise, did not increase skeletal muscle carnitine content, and therefore it is unlikely that increasing LC supplementation alters muscle metabolism during extreme exercise [251].

LC supplementation has been used in disorders that are characterized by low LC concentrations or impaired fatty acid oxidation, such as diabetes, sepsis, renal disease and cardiomyopathy [252]. For example, in patients with congestive heart failure propionyl-LC supplementation resulted in increased peak heart rate (increased mean by $12 \%$ ), exercise capacity (increased mean by $21 \%$ ) and peak oxygen consumption (increased mean by $45 \%$ ) in the treatment group [253].

Since the rate of mitochondrial oxidative phosphorylation naturally declines with age an important anti-aging use of LC has been to increase the rate of mitochondrial oxidative phosphorylation in aged populations. Feeding old rats acetyl-LC was found to reverse agerelated decreases in LC levels while increasing fatty acid metabolism. It also reversed the agerelated decline in cellular glutathione levels and improved muscle mitochondrial complex IV activity [251].

Dietary supplementation with LC and its various derivatives (up to $2 \mathrm{~g}$ per day) is a safe and potentially useful method to increase mitochondrial function [254]. Multiple clinical trials demonstrating its effectiveness in age-related chronic illnesses other than diabetes and cardiovascular diseases have not been conducted. One exception was a randomized, controlled clinical trial on 70 elderly subjects who were treated with LC for 6 months. At the beginning of the trial the aged subjects were generally found to have muscle weakness, decreasing mental health, impaired mobility and poor endurance. By the end of the study the treated group showed significant improvements in physical fatigue, mental fatigue and fatigue severity. They also displayed reductions in total fat mass, increased muscle mass and an increased capacity for physical and cognitive activity through reduced fatigue and improved cognitive function [255]. Other clinical trials on alcoholism, hepatic encephalopathy, coronary heart diseases, Peyronie's disease, cerebral ischemia and infertility indicate that supplementation with LC can have positive effects (reviewed in [254]).

\section{Alpha-Lipoic Acid (ALA)}

ALA (1,2-dithiolane-3-pentanoic acid) is a potent antioxidant, transition metal ion chelator, redox transcription regulator and anti-inflammatory agent [257]. ALA acts as a critical cofactor in mitochondrial $\square$-ketoacid dehydrogenases, and it is important molecule in mitochondrial oxidative decarboxylation [257, 258]. Clinically ALA has been used as an oral supplement in the treatment of complications associated with diabetes mellitus, and it has been shown to bring about improvements in various diabetic-associated neuropathies, inflammation and vascular 
health [245]. These effects have been attributed mainly to ALA having signal transduction effects on gene regulation and glucose uptake and metabolism [259].

During aging and in many chronic diseases certain sphingolipids, especially ceramides and in particular short-chain ceramides, accumulate in mitochondria due to hydrolysis of sphingomyelin by sphingomyelinase. Eventually this retards electron transport activity [260, 261]. Ceramide accumulation in mitochondria is especially damaging in cardiac tissue, so in aging rodents $\square$ ALA has been used to lower ceramide levels in the vascular endothelial cells of cardiac muscle by inhibiting sphingomyelinase activity. This resulted in restoration of mitochondrial glutathione levels and increasing electron transport function [262].

As previously discussed, in diabetes ALA has been used to reduce diabetic complications, such as sensorimotor polyneuropathies [263]. A blinded study demonstrated its clinical utility with some neuropathic impairments improving significantly on $\square$-Lipoic acid (but not nerve conduction attributes) [264]. The long-term use of ALA has proven to be safe in diabetic patients [264].

Given as an oral supplement ALA is rarely present in tissues above micromolar levels; therefore, it is unlikely to be an important cellular antioxidant [258]. However, an important property of ALA is its ability to increase cellular glutathione levels by regulating glutathione synthesis and thus indirectly reducing oxidative stress [252]. ALA can also modify the regulation of nuclear transcription factor NF- $\square \mathrm{B}$, and by doing this it can cause widespread transcriptional effects, resulting in the reduction of free radical and cytotoxic cytokine production [265]. As a transition metal chelater ALA can remove excess copper, iron and other metals that are involved in chronic diseases, such as hemochromatosis, end-stage renal failure, $\mathrm{AD}$ and $\mathrm{PD}$, and it is a potential therapeutic agent to prevent or mitigate heavy metal poisoning [256].

ALA has been shown to improve cognitive function along with mitochondrial function, suggesting a link between oxidative damage to mitochondria and congnition [266]. ALA has not been used in clinical trials on chronic fatigue, but its widespread use as a safe supplement (at doses of 200-600 mg/day) to support mitochondrial function and reduce oxidative stress has justified its incorporation into various anti-aging and mitochondrial support supplements [264, $265]$.

\section{Coenzyme Q10 (CoQ10)}

Ubiquinone or CoQ10 is a key mitochondrial cofactor and component of the mitochondrial electron transport chain and one of the most widely used natural supplements [243, 267]. It is also a strong antioxidant in its reduced form, and it can modify the expression of certain genes involved in cell signaling, metabolism and transport [267, 268]. The most important role of CoQ10 is its involvement in the transfer of electrons along the multiple complexes of the mitochondrial electron transport chain [267, 269]. It has been used in doses up to 1,200 mg per day, but most studies used lower doses [267].

CoQ10 is an essential component of the mitochondrial oxidative phosphorylation system, thus its supplementation in patients with reduced CoQ10 levels should result in increased mitochondrial energy production and reduced fatigue [267, 269]. A systematic review of the literature on the effects of CoQ10 on adaptive physical exercise, hypertension and heart failure 
revealed that most published studies showed modest improvements in exercise capacity in the subjects given oral CoQ10 [270]. In addition, in eight publications on the effects of CoQ10 on hypertension there was a mean decrease in systolic $(-16 \mathrm{~mm} \mathrm{Hg})$ and diastolic $(-10 \mathrm{~mm} \mathrm{Hg})$ blood pressure. In nine randomized trials on the use of CoQ10 in heart failure patients there were non-significant trends towards increased injection fraction and reduced mortality [270]. Rosenfeldt et al. performed their own three-month randomized, placebo-controlled trial on the effects of oral CoQ10 in patients with heart failure [270]. They found that in the test arm but not in the control arm patients showed significant improvements in symptoms and a trend towards improvements in mean exercise times [270].

As mentioned above, the anti-fatigue effects of oral CoQ10 during physical exercise have been examined in a blinded, cross-over trial [271]. Healthy subjects received CoQ10 or placebo for eight days, and their performance was evaluated at fixed workloads on a bicycle ergometer twice for two hr with a four hr rest in-between [271]. The subjects on CoQ10 were able to achieve higher work outputs, they reported less fatigue, and their need for a recovery period was alleviated compared to the placebo group [271]. This study indicated that CoQ10 is a useful supplement to improve fatigue and performance.

In patients with various diagnoses, such as neurodegenerative disease, CoQ10 has been used to reduce symptoms and delay progression [267, 269]. In AD models CoQ10 administration significantly delayed brain atrophy and typical $\beta$-amyloid plaque formation [272, 273]. In a randomized, placebo-controlled clinical trial on Alzheimer's patients that took an oral mixture of CoQ10, vitamins $\mathrm{C}$ and $\mathrm{E}$ and ALA in the test arm showed significant reductions in oxidative stress markers but failed to show significant changes in cerebrospinal fluid markers related to $\beta$ amyloid or tau pathology [273]. PD patients generally show increased oxidized-to-total CoQ10 ratios as well as significant increases in markers of oxidative damage in the cerebrospinal fluid, but this can be partially reversed with CoQ10 supplementation [274]. In patients with early Huntington's disease CoQ10 administration for 30 months slowed the usual decline in total functional capacity, but these differences did not reach statistical significance [275]. In contrast, in a multi-center placebo-controlled phase II trial with amyotrophic lateral sclerosis patients CoQ10 did not significantly modify functional decline over a nine-month period [276], and in genetic-based mitochondrial diseases CoQ10 plus several vitamins was shown to be ineffective [277].

\section{Reduced Nicotinamide Adenine Dinucleotide (NADH)}

NADH is a cellular redox cofactor in over 200 redox reactions and serves as substrate for certain enzymes [278, 279]. Cells have a universal requirement for NADH, and its deficiency results in a condition called pellagra, which is characterized by dermatitis, diarrhea, dementia and eventually leads to death [279]. In the mitochondria NADH delivers electrons from lipid and other metabolite hydrolysis to the electron transport chain, but in its reduced form NADH can also act as a strong antioxidant [278, 279].

Historically dietary NADH supplementation has been via NADH precursors, such as niacin, nicotinic acid or nicotinamide, but recently microcarriers have been used to stabilize oral NADH so that it can be directly absorbed in the gastrointestinal tract. This turns out to be more effective 
than using large oral doses of uncomplexed $\mathrm{NADH}$, which are prone to oxidation and degradation and are generally considered ineffective [280].

In many chronic diseases oxidative damage is extensive, and various mitochondrial antioxidants have been used to treat disease and delay progression [4-6, 243, 281-284]. Nowhere has this been more apparent than in neurodegenerative diseases [4, 5, 84, 86, 134, 239]. For example, in $\mathrm{AD}$ stabilized oral $\mathrm{NADH}$ has been used to improve cognitive functioning and dementia [278]; however, in another clinical trial there was no evidence of improvements in cognition or dementia using oral NADH [280]. In a controlled clinical trial AD patients were given stabilized NADH or placebo for six months, and it was found that the test group had significantly better performance scores than the placebo group (verbal fluency, visual construction and a trend toward increased performance on abstract verbal reasoning) [285]. However, there was no evidence of better performance using other measures (attention, memory) or on scores of dementia severity [285].

Stabilized oral NADH has also been used to reduce the symptoms of PD. In a preliminary open label clinical trial the effects of IV and oral NADH in over 800 Parkinson disease patients $19.3 \%$ of patients showed $30-50 \%$ improvement in disability, 58.8\% had moderate (10-30\%) improvement, and $21.8 \%$ did not respond to the therapy $(\mathrm{p}<0.01)$ [286]. Younger patients with a shorter duration of disease responded better and showed more significant improvements than older patients and patients with a longer duration of disease. The oral form was found to comparable to IV NADH in its effects [286]. However, when this type of trial was repeated statistically significant improvements in PD Rating scores were not found in patients treated with $\mathrm{NADH}$, and diferences were also not found in CSF clinical markers associated with PD severity [287].

Oral NADH has also been used in a stabilized form to reduce symptoms in patients with chronic fatigue. One such study on CFS patients used stabilized, oral NADH or placebo for four weeks in a cross-over trial [288]. Eight of 26 patients (30.7\%) responded positively to the microencapsulated NADH compared with 2 of $26(8 \%)$ in the placebo arm $(p<0.05)$ [288]. There was clearly an effect but only in a subset of patients in the trial. These results were not considered significant by Colquhoun and Senn [289]. A comparison of oral, stabilized NADH to psychological/nutritional therapy in 31 chronic fatigue syndrome patients revealed that stabilized $\mathrm{NADH}$ alone reduced fatigue in the first 4 months of a 12-month trial. After the first 4 months, however, symptom scores were similar in the NADH and the psychological/nutritional arms of the trial [290]. In another study stabilized NADH was given orally for two months to treat CFS patients with extensive fatigue [291]. Alegre et al. found in decreases in anxiety and maximum heart rate after a stress test, but there were little or no differences found in the functional impact of fatigue, quality of life, sleep quality, exercise capacity, or functional reserve [291]. The stabilized NADH alone has shown mixed results in various diseases and disorders, and not every patient responded to the oral, stabilized supplement [6].

\section{Lipid Replacement Theapy (LRT)}

The dietary replacement of cellular membrane phospholipids (LRT) using food-derived glyerolphosholipids to remove damaged, mainly oxidized, membrane lipids in mitochondria and other cellular organelles has proved very effective at increasing mitochondrial function and 
reducing fatigue $[6,7,212,244]$. To some degree antioxidant supplements can reduce ROS/RNS levels and prevent some mitochondrial membrane phospholipid oxidation, but antioxidants alone cannot repair the damage already done to cells, and in particular, to their mitochondrial inner membranes [7, 244].

The use of oral membrane phospholipids plus antioxidants in doses ranging from 500-2,000 mg per day has been effective in the treatment of various clinical conditions, such as CFS and other fatiguing illnesses (Table 2) [6, 7, 136, 212, 292, 293]. LRT results in the actual replacement of damaged membrane phospholipids with undamaged (unoxidized) lipids to ensure proper function of cellular and especially mitochondrial membranes. In these studies fatigue was monitored by use of the Piper Fatigue Scale (PFS) to measure clinical fatigue and quality of life [294].

Table 2. A partial list of ingredients/agents or supplements that have been used or suggested to treat mitochondrial dysfuction ${ }^{1}$

\section{Category Examples}

\begin{tabular}{ll} 
Vitamins & Vitamins C, D and E, Thiamine, Riboflavin \\
Minerals & Magnesium, Calcium, Phosphate \\
Lipids & Membrane Phospholipids, Unsaturated Fatty Acids \\
Metabolites & Creatine, Pyruvate \\
Cofactors & CoQ10, $\alpha$-Lipoic acid, NADH, nicotinic acid \\
Transporters & L-Carnitine, Membrane Phospholipids \\
Antioxidants & CoQ10, $\alpha$-Lipoic acid, NADH, Glutathione \\
Enzyme inhibitors & $\alpha$-Lipoic acid, Dichloroacetate \\
Herbs & Curcimin, Schisandrin \\
\hline
\end{tabular}

${ }^{1}$ Modified from Kerr [243] and Nicolson [6]

In a subsequent cross-over study the effects of LRT on fatigue and mitochondrial function were monitored in patients with moderate to severe chronic fatigue [212]. There was good correspondence between reductions in fatigue and gains in mitochondrial function. After 8 weeks of LRT with NTFactor, mitochondrial function was significantly improved, and after 12 weeks of NTFactor supplementation, fatigue was decreased by $35.5 \%(\mathrm{p}<0.001)$, and mitochondrial function was found to be similar to that found in young healthy adults (26.8\% increase, $\mathrm{p}<0.0001$ ) [212]. After 12 weeks of supplement use, subjects were placed on placebo for an additional 12 weeks, and their fatigue and mitochondrial function were again measured. After the placebo period, fatigue and mitochondrial function were intermediate between the initial values and those found after 8 or 12 weeks on the supplement, indicating that continued supplementation is required to show improvements in mitochondrial function and maintain lower fatigue scores [212].

Similar findings on fatigue reduction were observed in chronic fatigue syndrome and fibromyalgia syndrome patients given oral membrane phospholipids (NT Factor) [293]. Using a new formulation of NT Factor plus vitamins, minerals and other supplements in patients with 
moderate chronic fatigue resulted in a $36.8 \%$ reduction in fatigue within one week [295] (Table $3)$.

Table 3. Effects of Dietary LRT Supplement NTFactor ${ }^{\circledR}$ on Piper Fatigue Scores. ${ }^{1}$

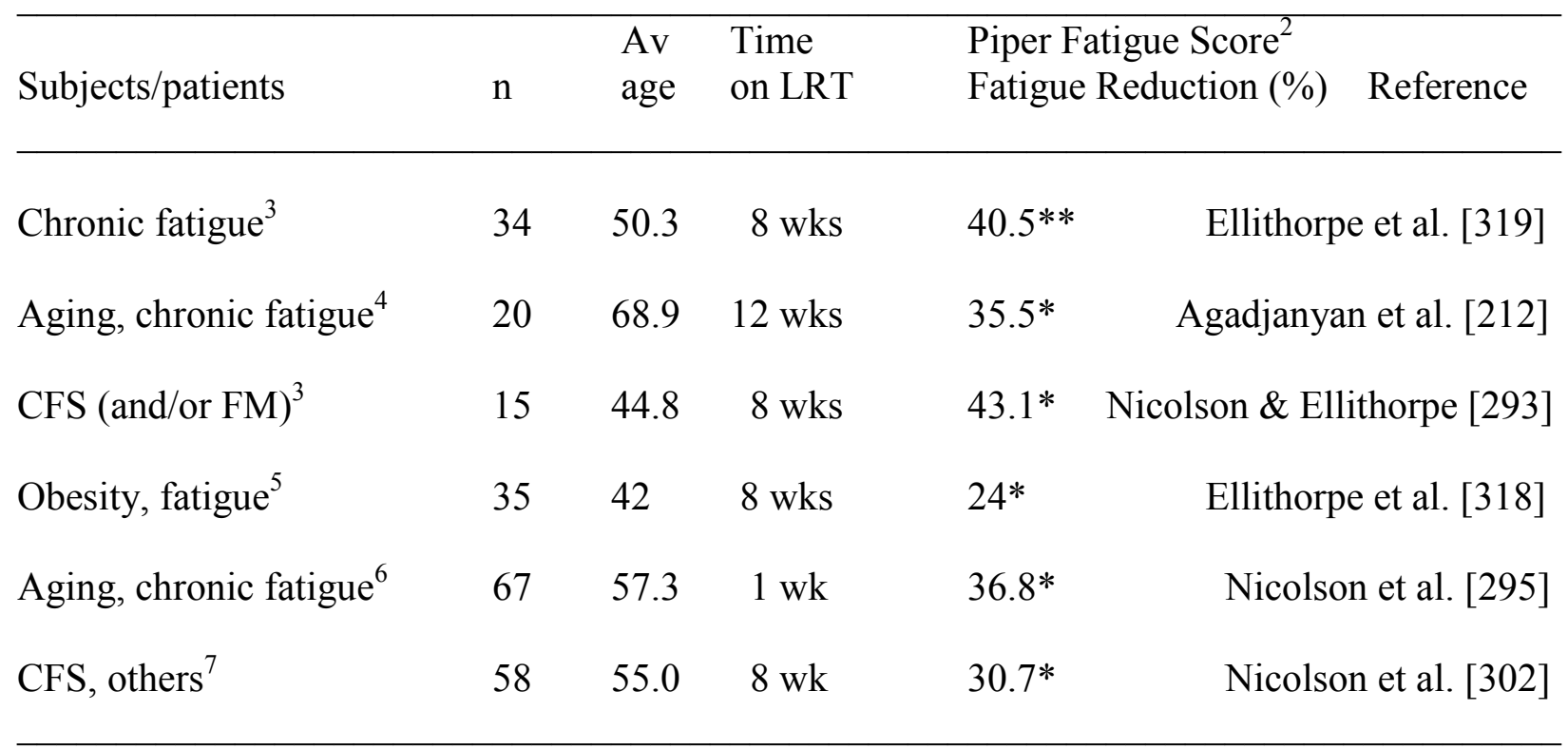

${ }^{1}$ Modified from Nicolson and Settineri [7]

${ }^{2}$ From Piper et al. [294]

${ }^{3}$ Propax $^{\text {TM }}$ with NT Factor ${ }^{\circledR}$

${ }^{4}$ NT Factor ${ }^{\circledR}$

${ }^{5}$ Healthy Curb ${ }^{\mathrm{TM}}$ with NT Factor ${ }^{\circledR}$

${ }^{6}$ Advanced Physician's Formula ${ }^{\mathrm{TM}}$ with NT Factor ${ }^{\circledR}$

${ }^{7}$ ATP Fuel ${ }^{\circledR}$ with NTFactor ${ }^{\circledR}$, CoQ10, NADH, LC, $\alpha$-keto glutaric acid $* * \mathrm{P}<0.0001, * \mathrm{P}<0.001$ compared to without NT Factor ${ }^{\circledR}$

\section{Vitamins and Minerals}

Vitamins, minerals and other small molecules fall into the category of micronutrients. They are essential in the support of mitochondrial function by providing antioxidants, cofactors, metal ions, salts, and other molecules that are essential in supporting the functions of mitochondrial enzymes, electron transport systems, mtDNA replication, fat and sugar metabolism, protein synthesis and proper antioxidant balance [296-298]. Vitamins, such as B (multiple), D, E, C, and ions, such as iron, magnesium, manganese, zinc, among other small molecules, are important $n$ this regard, and up to one-half of the aging North American population is deficient in these vitamins, minerals and other micronutrients [299].

The use of micronutrients in helping to restore and/or maintain mitochondrial function has proven useful in consert with other treatment modialties [296, 298, 300]. Although there are few clinical trials in the literature that demonstrate the usefulness and utility of supplementation with only vitamins, minerals, antioxidants and other micronutrients alone in supporting mitochondrial function, the ones that have been conducted clearly show the importance of providing adequate 
oral doses of vitamins, minerals, antioxidants and other micronutrients to maintain mitochondrial energy functions [296. 300-302]. However, their sole use in the treatment of mitochondrial diseases has proved disappointing [277]. But it is reassuring to find that many commercial mitochondrial supplements contain adequate amounts of these important molecules (for example [282, 292, 295, 302]). Thus in addition to vitamins, minerals, antioxidants and other micronutrients, other supplement components are likely required for significant and lasting effects on mitochondrial function.

\section{Combination Supplements to Restore Mitochondrial Function}

Oral supplements containing membrane phospholipids (NTFactor, 2,000 mg/day), CoQ10 (35 $\mathrm{mg}$ /day), microencapsulated NADH (35 mg/day), LC (160 mg/day), $\alpha$-ketoglutaric acid (180 $\mathrm{mg} /$ day) and other micronutrients have been combined into a dietary supplement (ATP Fuel ${ }^{\circledR}$ ) to treat fatigue and mitochondrial dysfunction [303]. This formulation was used in a study to treat long-term intractable fatigue in patients with a variety of diagnoses during a two-month trial.

The 58 participants in the ATP Fuel trial had moderate to severe intractable fatigue for an average $>17$ years and had been to an average of $>15$ practitioners without resolution of their fatigue. The study included 30 patients with chronic fatigue syndrome, 17 with chronic Lyme disease; 16 with other fatiguing illnesses, including fibromyalgia syndrome and Gulf War illness; 4 with autoimmune disease, including rheumatoid arthritis; 2 cancer; and 2 diabetes. These patients had tried unsuccessfully many drugs and supplements (average >35) to reduce their fatigue without success [303].

Participants in the trial included chronic illness patients who took the combination LRT supplement (ATP Fuel ${ }^{\circledR}$ ) for 8 weeks, and their fatigue was scored monthly [303]. The Piper Fatigue Score (PFS) is a validated instrument that measures four dimensions of subjective fatigue: behavioral/severity, affective/ meaning, sensory, and cognitive/mood [294]. These were used to calculate the four subscale/dimensional scores and the total fatigue scores. In this study the long-term chronic illness patients with intractable fatigue had initial PFS mean total fatigue scores of $7.51 \pm 0.29$, and after 8 weeks of supplement the mean scores improved to $5.21 \pm 0.28$, or a $30.7 \%$ reduction in fatigue $(\mathrm{p}<0.0001)$ [303].

The PFS fatigue scores can be further dissected into four subcategories: (i) Behavior/Severity subcategory, which deals with completing tasks, socializing, engaging in sexual activity and other activities, and intensity or degree of fatigue; (ii) Affective/Meaning subcategory, which determines whether the fatigue/tiredness is pleasant/unpleasant, whether the patient is agreeable/disagreeable, protective/destructive, or feels normal/abnormal; (iii) Sensory subcategory, which determines whether the patient is strong/weak, awake/sleepy, refreshed/tired, or energetic/unenergetic; and (iv) Cognitive/Mood subcategory, which assesses whether a patient feels relaxed/tense, exhilarated/depressed, able/unable to concentrate, remember, and think clearly) [294]. All of these fatigue subcategories showed significant reductions by the end of the 8 -week trial $(p<0.0001)$. For example, there was a $30.7 \%$ reduction $(p<0.0001)$ in severity/behavior of fatigue, indicating that there was a significant reduction in the intensity of fatigue, and a significant increase in the ability to complete tasks, socialize, and engage in sexual and other activities. Also, there was also a 28.0\% improvement $(\mathrm{p}<0.0001)$ in mood and cognitive ability, such as the ability to concentrate, remember, and think clearly [303]. 
The benefits of combining various natural mitochondrial support components into combination mitochondrial supplements should be obvious. Separate supplements are no longer required, and the individual components can be adjusted in dosage to provide maximal effectiveness. Also, with combined supplements patients who often have memory and other defects are more likely to be compliant than with the requirement of taking several separate supplements on a daily basis. New formulations can be designed to replace damaged mitochondrial components and also address particular protective needs, such as preconditioning to defend against oxidative stress, damage to ion channels and other needs [304].

\section{Final Comments}

There is ample evidence that intracellular infections are linked to mitochondria and mitochondrial dysfunction. Mitochondria play essential roles in cellular homeostasis through control of cell death and as sentinels of cellular danger, such as oxidative stress, loss of essential growth and maintenance factors, physical damage and infection by foreign agents [305-307]. They also orchestrate cellular adaptive danger responses to sustain cell survival, especially when infections threaten cellular systems [307, 308]. However, microorganisms have evolved with different strategies to evade or circumvent host mechanisms to identify, neutralize and degrade them [308-310].

During infection and cellular invasion by microorganisms coordination of multiple innate immune signaling pathways occurs through different pathogen-associated molecular pattern recognition receptors. The recognition of foreign invaders (and other danger molecules) by these innate receptors (Patern Recognition Receptors) can initiate an intracellular signaling cascade that results in activation of anti-microbial mechanisms to clear the infection [311,312].

Mitochondria have emerged as critical regulators of innate immune responses to invading pathogens as well as other stressors [311-313]. They initiate immune signaling modulators that are tightly linked to mitochondrial energetics through intracellular danger-sensing multiprotein platforms called inflammasomes [12, 313, 314]. Thus mitochondria operate as fundamental "hubs" in the pathways from detection of intracellular pathogens to adaptive responses that attempt to neutralize and eliminate pathogens as well as housing crucial signal transducers and providing a structural scaffold that is involved in regulating anti-microbial activities [305, 306]. They also warn the host with danger signals by providing multiple mitochondrial damage products (DAMPS) that are recognized by the innate immune system, resulting in the stimulation of local or systemic immune responses [315].

Mitochondria are addionally implicated in pathways that result in the cellular destruction of pathogens by autophagy through specialized autophagosomes [304, 307]. When pathogens damage cells beyond their ability to be repaired, mitochondria are also involved in initiating and removing the damaged cells by apoptosis [304, 316]. They not only modulate apoptosis triggered by terminal alternations in intracellular homeostasis, but they can also participate in apoptosis stimulated by responses to extracellular or external signals [317, 318]. Thus mitochondria are intrinsically tied to cellular infections in a number of ways.

Oral mitochondrial supplements containing various mitochondrial substrates, cofactors, precursors, components and modulators have proven useful in maintaining and improving mitochondrial function in various chronic diseases. In some examples cited in here this has 
resulted in reduction of specific illness signs and symptoms, improvements in quality of life and assistance in over-all recovery. Future efforts to refine and improve oral mitochondrial supplements and apply them clinically should enhance our abilities to treat and care for chronic illness patients as well as improve quality of life for aging populations.

\section{List of Abbreviations Used}

AD, Alzheimer's disease; ALA, $\alpha$-Lipoic acidALS, amyotrophic lateral sclerosis; ASD, autism spectrum disorders; CFS, chronic fatigue syndrome; CI, confidence interval; CMV, cytomegalovirus; CoQ10, coenzyme Q10; CSF, cerebrospinal fluid; CNS, central nervous system; ELISA, enzyme linked immunoabsorbant assay; HHV human herpes virus; HSV, herpes simplex virus; LC, L-carnitine; LRT, Lipid Replacement Therapy; MS, multiple sclerosis; NADH, Reduced Nicotinamide Adenine Dinucleotide;PCR, polymerase chain reaction; PD, Parkinson's disease RNS, Nitrogen Reactive Species; ROS, Reactive Oxygen Species

\section{Competing Interests}

The authors have no financial interests or conflicts of interest.

\section{Authors' Contributions}

All authors contributed to this review.

\section{Acknowledgements and Funding}

The authors would like to thank Nutritional Therapeutics, Inc. and Researched Nutritionals, Inc. for research and clinical trial financial support.

\section{References}

1. Nicolson GL. Chronic infections in neurodegenerative and neurobehavioral diseases. Lab Med 2008; 39(5): 291-299.

2. Nicolson GL, Haier J. Role of chronic bacterial and viral Infections in neurodegenerative, neurobehavioral, psychiatric, autoimmune and fatiguing illnesses: Part 1. Brit J Med Practit 2009; 2(4): 20-28.

3. Nicolson GL, Haier J. Role of chronic bacterial and viral Infections in neurodegenerative, neurobehavioral, psychiatric, autoimmune and fatiguing illnesses: Part 2. Brit J Med Practit 2010; 3(1): 301-311.

4. Reddy PH. Mitochondrial medicine for aging and neurodegenerative diseases. Neuromolec Med 2008; 10(4): 291-315.

5. Reddy PH, Reddy TP. Mitochondria as a therapeutic target for aging and neurodegenerative diseases. Curr Alzheimer Res 2011; 8(4): 393-409.

6. Nicolson GL. Mitochondrial dysfunction and chronic disease: treatment with natural supplements. Alt Ther Health Med 2013; 19: at5027. [Epub ahead of print].

7. Nicolson GL, Settineri R. Lipid Replacement Therapy: a functional food approach with new formulations for reducing cellular oxidative damage, cancer-associated fatigue and the adverse effects of cancer therapy. Funct Food Health Dis 2011; 1(4): 135-160. 
8. De Chiara G, Marococci ME, Sgarbanti R, Civitelli L, Ripoli C, Placentini R, Garaci E, Grassi C, Palamara AT. Infectious agents and neurodegeneration. Mol Neurobiol 2012; 46(3): 614-638.

9. Bach JF. Infections and autoimmune diseases. J Autoimmun 2005; 25(suppl): 74-80.

10. Sherbet G. Bacterial infections and the pathogenesis of autoimmune conditions. Brit $\mathbf{J}$ Med Practit 2009; 2(1): 6-13.

11. Nicolson GL, Haier J, Nasralla M, Nicolson NL, Ngwenya R, De Meirleir K. Mycoplasmal infections in Chronic Fatigue Syndrome, Fibromyalgia Syndrome and Gulf War Illness. J Chronic Fatigue Syndr 2000; 6(3): 23-39.

12. Verdon ME, Sigal LH. Recognition and management of Lyme Disease. Am Family Physician 1997; 56: 427-436.

13. Homer MJ, Aguilar-Delfin I, Telford SR $3^{\text {rd }}$, Krause PJ, Persing DH. Babesiosis. Clin Microbiol Rev 2000; 13: 451-469.

14. Kizilkilic O, Calli C. Neurobrucellosis. Neuroimaging Clin N Am 2011; 21: 927-937.

15. Galley HF. Oxidative stress and mitochondrial dysfunction in sepsis. Brit $\mathbf{J}$ Anaesth 2011; 107: 57-64.

16. Pessayre D, Fromenty B, Mansouri A. Mitochondrial injury in steatohepatitis. Eur J gastroenterol Hepatol 2004; 16: 1-11.

17. Rusconi B, Greub G. Chlamydiales and the innate immune response: friend or foe? FEMS Immunol Med Microbiol 2011; 61: 231-244.

18. Richter C, Par JW, Ames B. Normal oxidative damage to mitochondrial and nuclear DNA is extensive. Proc Nat Acad Sci USA 1998; 85: 6465-6467.

19. Stadtman E. Introduction to serial reviews on oxidatively modified proteins in aging and disease. Free Radical Biol Med 2002; 32: 789.

20. Spector AA, Yorek MA. Membrane lipid composition and cellular function. J Lipid Res 1985; 26: 101-105.

21. Nicolson GL. Diagnosis and therapy of chronic systemic co-infections in Lyme Disease and other tick-borne infectious diseases. Townsend Lett 2007; 285: 93-98.

22. Burrascano JJ. Diagnostic hints and treatment guidelines for Lyme and other tick-borne diseases. In: Advanced Topics in Lyme Disease, Managing Lyme Disease, $16^{\text {th }}$ edition, 5-28, 2008.

23. Muravchick S, Levy RJ. Clinical implications of mitochondrial dysfunction. Anesthesiol 2006; 105: 819-837.

24. Keen D, Ward S. Autistic Spectrum Disorder. Autism 2004; 8: 39-58.

25. Fatemi SH, Reutiman TJ, Folsom TD, Sidwell RW. The role of cerebellar genes in pathology of autism and schizophrenia. Cerebellum 2008; 99: 56-70.

26. Nicolson GL, Gan R, Nicolson NL, Haier J. Evidence for Mycoplasma, Chlamydia pneunomiae and HHV-6 co-infections in the blood of patients with Autism Spectrum Disorders. J Neurosci Res 2007; 85: 1143-1148.

27. Bransfield RC. Preventable cases of autism: relationship between chronic infectious diseases and neurological outcome. Pediat Health 2009; 3(2): 125-140.

28. Muhle R, Trentacoste SV, Rapin I. The genetics of autism. Pediatr 2004; 113: 72-86. 
29. Dhillon VS, Fenech M. Mutations that affect mitochondrial functions and their association with neurodegenerative diseases. Mutat Res 2013; Sept 17 doi: 10.1016/j.mrrev.2013.09.001 [Epub ahead of print].

30. Frye RE, Delatorre R, Taylor H, Slattery J, Melnyk S, Chowdhury N, James SJ. Redox metabolism abnormalities in autistic children associated with mitochondrial disease. Transl Psychiatry 2013; 3: e273 [Epub ahead of print].

31. Deth R, Muratore C, Benzercry J, Power-Charnitsky VA, Waly M. How environmental and genetic factors combine to cause autism: a redox/methylation hypothesis. Neurotoxicol 2008; 29: 190-201.

32. Mattson MP. Infectious agents and age-related neurodegenerative disorders. Ageing Res Rev 2004; 3: 105-120.

33. Bazala E, Renda J. Latent Chlamydial infections: the probably cause of a wide spectrum of human diseases. Med Hypotheses 2005; 65: 578-584.

34. Williams DB, Windebank AJ. Motor neuron disease (Amyotrophic Lateral Sclerosis). Mayo Clinic Proc 1991; 66: 54-82.

35. Walling AD. Amyotrophic Lateral Sclerosis: Lou Gehrig's Disease. Am Family Physician 1999; 59: 1489-1496.

36. Berger MM, Kopp N, Vital C, Redi B, Aymard M, Lina B. Detection and cellular localization of enterovirus RNA sequences in spinal cord of patients with ALS. Neurology 2000; 54: 20-25.

37. Walker MP, Schlaberg R, Hays AP, Bowser R, Lipkin WI. Absence of echovirus sequences in brain and spinal cord of amyotrophic lateral sclerosis patients. Ann Neurol 2001; 49: 249-253.

38. Nicolson GL, Berns P, Nasralla M, Haier J, Pomfret J. High frequency of systemic mycoplasmal infections in Gulf War veterans and civilians with Amyotrophic Lateral Sclerosis (ALS). J Clin Neurosci 2002; 9: 525-429.

39. Halperin JJ, Kaplan GP, Brazinsky S, Tsai TF, Cheng T, Ironside A, Wu P, Delfiner J, Golightly M, Brown RH. Immunologic reactivity against Borrelia burgdorferi in patients with motor neuron disease. Arch Neurol 1990; 47: 586-594.

40. Hansel Y, Ackerl M, Stanek G. ALS-like sequelae in chronic neuroborreliosis. Wien Med Wochensch 1995; 147: 186-188.

41. Qureshi M, Bedlack RS, Cudkowicz ME. Lyme disease serology in amyotrophic lateral sclerosis. Muscle Nerve 2009; 40: 626-628.

42. MacDonald AB. Spirochetal cyst forms in neurodegenerative disorders, hiding in plain site. Med Hypotheses 2006; 67: 819-832.

43. Hugan J. ALS therapy: targets for the future. Neurol 1996; 47(suppl 4): S251-S254.

44. McCormick AL, Brown RH Jr, Cudkowicz ME, Al-Chalabi A, Garson JA. Quantification of reverse transcriptase in ALS and elimination of a novel retroviral candidate. Neurol 2008; 70: 278-283.

45. Stipa G, Taiuti R, de Scisciolo G, Ametoli G, Tredici MR, Biondi N, Barsanti L, Lolli F. Sporadic amyotrophic lateral sclerosis as an infectious disease: a possible role of cyanobacteria? Med Hypotheses 2006; 67: 1363-1371. 
46. Cozzolino M, Ferri A, Valle C, Carri MT. Mitochondria and ALS: implications from novel genes and pathways. Mol Cell Neurosci 2013; 55: 44-49.

47. Cozzolino M, Pesaresi MG, Gerbino V, Grosskreutz J, Carr MT. Amyotrophic lateral sclerosis: new insights into underlying molecular mechanisms and opportunities for therapeutic intervention. Antiox Redox Signal 2012; 9: 1277-1330.

48. Parakh S, Spencer DM, Halloran MA, Soo KY, Atkin JD. Redox regulation in Amyotrophic Lateral Sclerosis. Oxid Med Cell Longev 2013; 2013: 408681. doi: $10.1155 / 2013 / 408681$.

49. Sobel RA. The pathology of multiple sclerosis. Neurol Clinic 1995; 13: 1-21.

50. Bruck W. Clinical implications of neuropathological findings in multiple sclerosis. J Neurol 2005; 252(suppl 3): 10-14.

51. Muñoz-Culla M, Irizar H, Otaegui D. The genetics of multiple sclerosis: review of current and emerging candidates. Appl Clin Genet 2013; 8: 63-73.

52. Huynh JL, Casaccia P. Epigenetic mechanisms in multiple sclerosis: implications for pathogenesis and treatment. Lancet Neurol 2013; 12(2): 195-206.

53. Baranzini SE, Oksenberg JR. Genomics and new targets for multiple sclerosis. Pharmacogenomics 2005; 6: 151-161.

54. Currier RD, Eldridge R. Possible risk factors in multiple sclerosis as found in a national twin study. Arch Neurol 1982; 39: 140-44.

55. Greenlee JE, Rose JW. Controversies in neurological infectious diseases. Semin Neurol 2000; 20: 375-386.

56. Gilden DH. Infectious causes of multiple sclerosis. Lancet Neurol 2005; 4: 195-202.

57. Malmone D, Gregory S, Arnason BG, et al. Cytokine levels in the cerebrospinal fluid and serum of patients with multiple sclerosis. J Neuroimmunol 1991; 32: 87-74.

58. Woodroofe MN. Cytokine production in the central nervous system. Neurol 1995; 45 (Suppl 6): S6-S10.

59. Sriram S, Mitchell W, Stratton C. Multiple sclerosis associated with Chlamydia pneumoniae infection of the CNS. Neurol 1998; 50: 571-572.

60. Sriram S, Stratton CW, Yao S, Tharp A, Ding L, Bannan JD, Mitchell WM. Chlamydia pneumoniae infection of the central nervous system in multiple sclerosis. Ann Neurol 1999; 46: 6-14.

61. Yao S-Y, Stratton CW, Mitchell WM, Sriram S. CFS oligoclonal bands in MS include antibodies against Chamydophila antigens. Neurol 2001; 51: 1168-1176.

62. Contini C, Seraceni S, Castellazzi M, et al. Chlaymdophila pneumoniae DNA and mRNA transcript levels in peripheral blood mononuclear cells and cerebrospinal fluid of patients with multiple sclerosis, Neurosci Res 2008; 62: 58-61.

63. Sriram S, Ljunggren-Rose A, Yao S-Y, Whetsell WO Jr. Detection of chlamydial bodies and antigens in the central nervous system of patients with multiple sclerosis. $\mathrm{J}$ Infect Dis 2005; 192: 1219-1228.

64. Contini C, Cultrera R, Seraceni S, Castellazzi M, Granieri E, Fainardi E. Cerebrospinal fluid molecular demonstration of Chlamydia pneumoniae DNA is associated to clinical and brain magnetic resonance imaging activity in a subset of patients with relapsingremitting multiple sclerosis. Multiple Sclerosis 2004; 10: 360-369. 
65. Grimaldi LM, Pincherle A, Martinelli-Boneschi F, Filippi M, Patti F, Reggio A, Franciotta D, Allegra L, Comi G, Blasi F. An MRI study of Chlamydia pneumoniae infection in Italian multiple sclerosis patients. Multiple Sclerosis 2003; 9: 467-471.

66. Dong-Si T, Weber J, Liu YB, Buhmann C, Bauer H, Bendl C, Schnitzier P, GrondGinsbach C, Grau AJ. Increased prevalence of and gene transcription by Chlamydia pneumoniae in cerebrospinal fluid of patients with relapsing-remitting multiple sclerosis. J Neurol 2004; 251: 542-547.

67. Stratton CW, Sriram S. Association of Chlamydia pneumoniae with central nervous system disease. Microbes Infect 2003; 5: 1249-1253.

68. Stratton CW, Wheldon DB. Multiple sclerosis: an infectious syndrome in ving Chlamydophia pneumoniae. Trends Microbiol 2006; 14: 474-479.

69. Boman J, Roblin PM, Sundström P, Sundström M, Hmmerschlag MR. Failure to detect Chlamydia pneumoniae in central nervous system of patients with MS. Neurol 2000; 11: 265.

70. Pucci E, Taus C, Cartechini E, Morelli M, Giuliani G, Clementi M, Menzo S. Lack of Chlamydia infection of the central nervous system in multiple sclerosis. Ann Neurol 2000; 48: 399-400.

71. Hammerschlag MR, Ke Z, Lu F, Roblin P, Boman J, Kalman B. Is Chlamydia pneumoniae present in brain lesions of patients with multiple sclerosis? J Clin Microbiol 2000; 38: 4274-4276.

72. Swanborg RH, Whittum-Hudson JA, Hudson AP. Infectious agents and multiple sclerosis-Are Chlamydia pneumoniae and human herpes virus 6 involved? J Neuroimmunol 2003; 136: 1-8.

73. Nicolson GL. Systemic intracellular bacterial infections (Mycoplasma, Chlamydia, Borrelia species) in neurodegenerative (Alzheimers, MS, ALS) and behavioral diseases (Autistic Spectrum Disorders). Townsend Lett 2008; 295: 74-84.

74. Sanders VJ, Felisan S, Waddell A, Tourtellotte WW. Detection of herpesviridae in postmortem multiple sclerosis brain tissue and controls by polymerase chain reaction. $\mathrm{J}$ Neurovirol 1996; 2: 249-258.

75. Sanders VJ, Felisan S, Waddell A, et al. Detection of herpesviridae in postmortem multiple sclerosis brain tissue and controls by polymerase chain reaction. J Neurovirol 1996; 2: 249-58.

76. Challoner PB, Smith KT, Parker JD, MacLeod DL, Coulter SN, Rose TM, Schultz ER, Bennett JL, Garber RL, Chang M. Plaque-associated expression of human herpesvirus 6 in multiple sclerosis. Proc Natl Acad Sci USA 1995; 92: 7440-7444.

77. Sola P, Merelli E, Marasca R, Poggi M, Luppi M, Montorsi M, Torelli G. Human herpesvirus-6 and multiple sclerosis: survey of anti-HHV-6 antibodies by immunofluorescence analysis and viral sequences by polymerase chain reaction. $\mathbf{J}$ Neurol Neurosurg Psychiat 1993; 56: 917-919.

78. Kuusisto H, Hyöty H, Kares S, Kinnunen E, Elovaara I. Human herpes virus 6 and multiple sclerosis: a Finnish twin study. Mult Scler 2008; 14: 54-58.

79. Steiner I, Nisipianu P, Wirguin I. Infection and etiology and pathogenesis of multiple sclerosis. Curr Neurol Neurosci Rep 2001; 1: 271-76. 
80. Giraudon P, Bernard A. Chronic viral infections of the central nervous system: aspects of specific to multiple sclerosis. Rev Neurol (Paris) 2009; 169: 789-795.

81. Frykholm BO. On the question of infectious aetiologies for multiple sclerosis, schizophrenia and the chronic fatigue syndrome and the treatment with antibiotics. Med Hypotheses 2009; 72: 736-739.

82. Lassmann H. Pathology and disease mechanisms in different stages of multiple sclerosis. J Neurol Sci 2013; Jun 2. doi: 10.1016/j.jns.2013.05.010.

83. Campbell GR, Ohno N, Turnbull DM, Mahad DJ. Mitochondrial changes within axons in multiple sclerosis: an update. Curr Opin Nuerol 2012; 4: 169. doi: 10.1097/WCO. 0b013e3283533a25.

84. Su K, Bourdette D, Forte M. Mitochondrial dysfunction and neurodegeneration in multiple sclerosis. Front Physiol 2013; 4: 169. doi: 10.3389/fphys.2013.00169.

85. Broadwater L, Pandit A, Clements R, Azzam S, Vadnal J, Sulak M, Yong VW, Freeman EJ, Gregory RB, McDonough J, Analysis of the mitochondrial proteome in multiple sclerosis cortex. Biochim Biophys Acta 2011; 1812: 630-641.

86. Su K, Bourdette D, Fore M. Mitochondrial dysfunction and neurodegeneration in multiple sclerosis. Front Physiol 2013; July 25 doi: 10.3389/fphys.2013.00169.

87. Nicholls DG. Mitochondrial ion circuits. Essays Biochem 2010; 47: 25-35.

88. Mahad D, Lassmann H, Turnbull D. Review: mitochondria and disease progression in multiple sclerosis. Neuropathol Appl Neurobiol 2008; 34: 577-589.

89. Masters CL, Beyreuther K. Alzheimer's centennial legacy: prospects for rational therapeutic intervention targeting the Abeta amyloid pathway. Brain 2006; 129: 28232839.

90. Drachman DA. Aging of the brain, entropy, and Alzheimer Disease. Neurol 2006; 67: 1340-1352.

91. Markesbery WR, Lovell MA. Damage to lipids, proteins, DNA and RNA in mild cognitive impairment. Arch Neurol 2007; 64: 954-956.

92. Daly MP. Diagnosis and management of Alzheimer Disease. J Am Board Family Pract 1999; 12: 375-385.

93. Holmes C, El-Okl M, Williams AL, Cunningham C, Wilcockson D, Perry VH. Systemic infection, interleukin 1-beta and cognitive decline in Alzheimer's disease. J Neurol Neurosurg Psychiat 2003; 74: 788-789.

94. Balin BJ, Appelt DM. Role of infection in Alzheimer's Disease. J Am Osteopath Assoc 2001; 101(suppl 12): S1-S6.

95. Yucesan C, Sriram S. Chlamydia pneumoniae infection of the central nervous system. Curr Opin Neurol 2001; 14: 355-359.

96. Balin BJ, Gerard HC, Arking EJ, Appelt DM, Branigan JP, Abrams JT, WhittumHudson JA, Hudson AP. Identification and localization of Chlamydia pneumoniae in the Alzheimer's brain. Med Microbiol Immunol 1998; 187: 23-42.

97. Gerard HC, Dreses-Werringloer U, Wildt KS, Deka S, Oszust C, Balin BJ, Frey WH $2^{\text {nd }}$, Bordayo EZ, Whittum-Hudson JA, Hudson AP. Chlamydophila (Chlamydia) 
penumoniae in the Alzheimer's brain. FEMS Immunol Med Microbiol 2006; 48: 355 366.

98. MacIntyre A, Abramov R, Hammond CJ, Hudson AP, Arking EJ, Little CS, Appelt DM, Balin BJ. Chlamydia pneumoniae infection promotes the transmigration of monocytes through human brain endothelial cells. J Neurosci Res 2003; 71: 740-750.

99. Dreses-Werringloer U, Bhuiyan M, Zhao Y, Gérard HC, Whittum-Hudson JA, Hudson AP. Initial characterization of Chlamydophila (Chlamydia) pneumoniae cultured from the late-onset Alzheimer brain. Intern J Med Microbiol 2998; 299: 187-201.

100. Hammond CJ, Hallock LR, Howanski RJ, Appelt DM, Balin BJ. Immunohistological detection of Chlamydia pneumoniae in the Alzheimer's disease brain. BMC Neurosci 2010; 11: 121. doi: 10.1186.1471-2202-11-121.

101. Little CS, Hammond CJ, MacIntyre A, Balin BJ, Appelt DM. Chlamydia pneumoniae induces Alzheimer-like amyloid plaques in brains of BALB/c mice. Neurobiol Aging 2004; 25: 419-429.

102. Gieffers J, Reusche E, Solbach W, Maass M. Failure to detect Chlamydia pneumoniae in brain sections of Alzheimer's Disease patients. J Clin Microbiol 2000; 38: 881-882.

103. Meer-Scherrer L, Chang-Loa C, Adelson ME, Mordechai E, Lobrinus JA, Fallon BA, Tilton RC. Lyme disease associated with Alzheimer's Disease. Curr Microbiol 2006; 52: 330-332.

104. Miklossy J, Khalili K, Gern L, Eircson RL, Darekar P, Bolle L, Hurlimann J, Paster BJ. Borrelia burgdorferi persists in the brain in chronic Lyme neuroborreliosis and may be associated with Alzheimer's disease. J Alzheimers Dis 2004; 6: 639-649.

MacDonald AB. Alzheimer's Disease Braak Stage progressions: reexamined and redefined as Borrelia infection transmission through neural circuits. Med Hypotheses 2007; 68: 1059-1064.

106. MacDonald AB. Plaques of Alzheimer's Disease originate from cysts of Borrelia burgdorferi, the Lyme Disease spirochete. Med Hypotheses 2006; 67: 592-600.

107. Miklossy J, Kis A, Radenovic A, Miller L, Forro L, Martins R, Reiss K, Darbinian N, Darekar P, Mihaly L, Khalili K. Beta-amyloid deposition and Alzheimer's type changes induced by Borrelia spirochetes. Neurobiol Aging 2006; 27: 228-236.

108. Glabe C. Intracellular mechanisms of amyloid accumulation and pathogenesis in Alzheimer's Disease. J Molec Neurosci 2001; 17: 137-145.

109. Marques AR, Weir SC, Fahle GA, Fischer SH. Lack of evidence of Borrelia involvement in Alzheimer's Disease. J Infect Dis 2000; 182: 1006-1007.

110. Miklossy J. Chronic inflammation and amyloidogenesis in Alzheimer's disease-role of spirochetes. J Alzheimers Dis 2008; 13: 381-391.

111. Miklossy J. Emerging roles of pathogens in Alzheimer disease. Expert Rev Mol Med 2011; 13: e30. doi: 10.1017/S1462399411002006.

112. Kountouras J, Boziki JM, Gavalas E, Zavos C, Deretzi G, Grigoriadis N, Tsolaki M, Chatzopoulos D, Katsinelos P, Tzilves D, Zabouri A, Michailidou I. Increased cerebrospinal fluid Helicobacter pylori antibiody in Alzheimer's disease. Intern J Neurosci 2009; 119: 765-767. 
113. Robinson SR, Dobson C, Lyons J. Challenges and directions for the pathogen hypothesis of Alzheimer's disease. Neurobiol Aging 2004; 25: 629-637.

114. Denaro FJ, Staub P, Colmer J, Freed DM. Coexistance of Alzheimer's disease neuropathology with herpes simplex encephalitis. Cell Molec Biol 2003; 49: 12331240.

115. Itzhaki RF, Wozniak MA. Herpes simplex virus type 1 in Alzheimers's disease: the enemy within. J Alzheimers Dis 2008; 13: 393-405.

116. Lin WR, Shang D, Itzhaki RF. Neurotrophic viruses and Alzheimer's Disease: Interaction of Herpes Simplex type-1 virus and apolipoprotein E in the etiology of the disease. Molec Chem Neuropathol 1996; 28: 135-141.

117. Itzhaki RF, Dobson CB, Lin WR, Wozniak MA. Association of HSV1 and apolipoprotein E-varepsiolon4 in Alzheimer's disease. J Neurovirol 2001; 7: 570-571.

118. Shipley SJ, Parkin ET, Itzhaki RF, Dobson CB. Herpes Simplex virus interferes with amyloid precursor protein processing. BMC Microbiol 2005(Aug 18); 5: 48.

119. Wozniak MA, Itzhaki RF, Shipley SJ, Dobson CB. Herpes simplex virus infection causes cellular beta-amyloid accumulation and secretase upregulation. Neurosci Lett 2007; 429: 95-100.

120. Lin WR, Wozniak MA, Wilcock GK, Itzhaki RF. Cytomegalovirus is present in a very high proportion of brains from vscular dementia patients. Neurobiol Dis 2002; 9: 8287.

121. Reddy PH. Mitochondrial oxidative damage in aging and Alzheimer's disease: implications for mitochondrially targeted antioxidant therapies. J Biomed Biotechnol 2006; 2006: 31372.

122. Leuner K, Hauptmann S, Abdel-Kader R, Scherping I, Keil U, Strosznajder JB, Eckert A, Muller WE. Mitochondrial dysfunction: the first domino in brain aging and Alzheimer's diseases? Antioxid Redox Signal 2007; 9: 1659-1675.

123. Hauptmann S, Keil U, Scherping I, Bonert A, Eckert A, Müller WE. Mitochondrial dysfunction in sporadic and genetic Alzheimer's disease. Exp Gerontol 2006; 41: 668673.

124. Keil U, Hauptmann S, Bonert A, Scherping I, Eckert A, Müller WE. Mitochondrial dysfunction induced by disease relevant AbetaPP and tau protein mutations. J Alzheimers Dis 2006; 9: 139-146.

125. Rhein V, Song X, Wiesner A, Ittner LM, Baysang G, Meier F, Ozmen L, Bluethmann H, Drose S, Brandt U, Svaaskan E, Czech C, Gotz J, Eckert A. Amyloid-beta and tau synergistically impair the oxidative phosphorylation system in triple transgenic Alzheimer's disease mice. Proc Natl Acad Sci USA 2009; 106: 20057-20062.

126. Wolters EC, Braak H. Parkinson's disease: premotor clinico-pathological correlations. J Neural Transmiss 2006; 70(suppl 1); 309-319.

127. Klockgether T. Parkinson's disease: clinical aspects. Cell Tissue Res 2004; 318: 115120.

128. Sulzer D. Multiple hit hypothesis for dopamine neuron loss in Parkinson's disease. Trends Neurosci 2007; 30: 244-250. 
129. Puschmann A. Monogenic Parkinson's disease and parkinsonism: clinical phenotypes and frequencies of known mutations. Parkinsonism Relat Disord 2013; 19: 407-415.

130. Singleton AB, Farrer MJ, Bonifati V. The genetics of Parkinson's disease: progress and therapeutic implications. Mov Disord 2013; 28: 14-23.

131. Fahn S. Description of Parkinson's disease as a clinical syndrome. Ann New York Acad Sci 2003; 991: 1-14.

132.Zuo L, Motherwell MS. The impact of reactive oxygen species and genetic mitochondrial mutations in Parkinson's disease. Gene 2013; 532: 18-23.

133. Zorzon M, Capus L, Pellegrino A, Cazzato G, Zivadinov R. Familial and environmental risk factors in Parkinson's disease: a case control study in north-east Italy. Acta Neurol Scand 2002; 105: 77-82.

134. Olanow CW, Arendash GW. Metals and free radicals in neurodegeneration. Curr Opin Neurol 1994; 7: 548-558.

135. Logroscino G. The role of early life environmental risk factors in Parkinson disease: what is the evidence? Environ Health Perspect 2005; 113: 1234-1238.

136. Stoessl AJ. Etiology of Parkinson's disease. Can J Nuerol Sci 1999; 26(suppl 2): S5S12.

137. Liu B, Gao HM, Hong JS. Parkinson's disease and exposure to infectious agents and pesticides and the occurrence of brain injuries: role of neuroinflammation. Environ Health Perspect 2003; 111: 1065-1073.

138. Vlajinac H, Dzoljic E, Maksimovic J, Marinkovic J, Sipetic S, Kostic V. Infections as a risk factor for Parkinson's disease: a case-control study. Intern J Neurosci 2013; 123 : 329-332.

139. Jenner P, Olanow CW. The pathogenesis of cell death in Parkinson's disease. Neurol 2006; 66(suppl 4): S24-S36, 2006.

140. Dobbs RJ, Dobbs SM, Bjarnason IT, Oxlade NL, Charlett A, Al-Janabi MA, Kerwin RW, Mahler RF, Price AB. Role of chronic infection and inflammation in the gastroinstestinal tract in the etiology and pathogenesis of idiopathic parkinsonism. Part 1: eradication of Helicobacter in the cachexia of idiopathic parkinsonism. Helicobacter 2005; 10: 267-275.

141. Pierantozzi M, Piertroiusti A, Sancesario G, Lunardi G, Fedele E, Giacomini P, Frasca S, Galante A, Marciani MG, Stanzione P. Reduced L-dopa absorption and increased clinical fluctuations in Helicobacter pylori-infected Parkinson's disease patients. Neurol Sci 2001; 22: 89-91.

142. Pierantozzi M, Piertroiusti A, Brusa L, Galati S, Stefani A, Lunardi G, Fedele E, Sancesario G, Bernadi G, Bergamaschi A, Magrini A, Stanzione P, Galante A. Helicobacter pylori eradication and L-dopa absorption in patients with PD and motor fluctuations. Neurol 2006; 66: 1824-1829.

143. Barker RA, Cahn AP. Parkinson's disease: an autoimmune process. Intern J Neurosci 1988; 43: 1-7.

144. Arai H, Furuya T, Mizuno Y, Mochizuki H. Inflammation and infection in Parkinson's disease. Histol Histopathol 2006; 21: 673-678. 
145. Wersinger C, Sidhu A. An inflammatory pathomechanism for Parkinson's disease. Curr Med Chem 2006; 13: 591-602.

146. Hald A, Lotharius J. Oxidative stress and inflammation in Parkinson's disease: is there a causal link? Exp Neurol 2005; 193: 279-290.

147. Ogata A, Tashiro K, Nukuzuma S, Nagashima K, Hall WW. A rat model of Parkinson's disease induced by Japanese encephalitis virus. J Neurovirol 1997; 3: 141-147.

148. Beaman BL, Canfield D, Anderson J, Pate B, Calne D. Site-specific invasion of the basal ganglia by Nocaardia asteriodes GUH-2. Med Microbiol Immunol 2000; 188: 161-168.

149. De Chiara G, Marcocci ME, Sgarbanti R, Civitelli L, Ripoli C, Piacentini R, Garaci E, Grassi C, Palamara AT. Infectious agents and neurodegeneration. Mol Neurobiol 2012; 46: 614-638.

150. Cassarino DS, Quezado MM, Ghatak NR, Duray PH. Lyme-associated parkinsonism: a neuropathologic case study and review of the literature. Arch pathol Lab Med 2003; 127: 1204-1206.

151. Ickenstein GW, Klotz JM, Langohr HD. Virus encepthalitis with symptomatic Parkinson syndrome, diabetes insipidus and panhypopituitarism. Fortschr Neurol Psychiat 1999; 67: 476-481.

152. Fazzini E, Fleming J, Fahn S. Cerebrospinal fluid antibodies to coronavirus in patients with Parkinson's disease. Movment Disord 1992; 7: 153-158.

153. Kim JS, Choi IS, Lee MC. Reversible parkinsonism and dystonia following Mycoplasma pneumoniae infection. Mov Disord 1995; 10: 510-512.

154. Maggi P, de Mari M, Moramarco A, Fiorentino G, Lamberti P, Angarano G. Parkinsonism in a patient with AIDS and cerebral opportunistic granulomatous lesions. Neurol Sci 2000; 21: 173-176.

155. Mattson MP. Infectious agents and age-related neurodegenerative disorders. Ageing Res Rev 2004; 3: 105-120.

156. Alasia DD, Asekomeh GA, Unachuku CN. Parkinsonism induced by sepsis: a case report. Niger J Med 2006; 15: 333-336.

157. Onyango IG. Mitochondrial dysfunction and oxidative stress in Parkinson's disease. Neurochem Res 2008; 33: 589-597.

158. Gandhi S, Wood NW. Molecular pathogenesis of Parkinson's disease. Hum Mol Genet 2005; 14: 2749-2755.

159. Matsuda S, Kitagishi Y, Kobayashi M. Function and characteristics of PINK1 in mitochondria. Oxid Med Cell Longev 2013; 2013: 601587. doi: 10.1155/2013/601587. [Epub before print].

160. Narendra DP, Youle RJ. Targeting mitochondrial dysfunction: role for PINK1 and Parkin in mitochondrial quality control. Antioxid Redox Signal 2011; 14: 1929-1938.

161. Matsuda N, Sato S, Shiba K, Okatsu K, Saisho K, Gautier CA, Sou YS, Saiki S, Kawajiri S, Sato F, Kimura M, Komatsu M, Hattori N, Tanaka K. PINK1 stabilized by mitochondrial depolarization recruits Parkin to damaged mitochondria and activates latent Parkin for mitophagy. J Cell Biol 2010; 189: 211-221. 
162. Johnson NL, Rodriguez D. Children with autism spectrum disorder at a pediatric hospital: a systematic review of the literature. Pediatr Nurs 2013; 39: 131-141.

163.Zwaigenbaum L, Bryson S, Garon N. Early identification of autism spectrum disorders. Behav Brain Res 2013; 251: 133-146.

164. Persico AM, Napolioni V. Autism genetics. Behav Brain Res 2013; 251: 95-112.

165.Zafeiriou DI, Ververi A, Dafoulis V, Kayyva E, Vargiami E. Autism spectrum disorders: the quest for genetic syndromes. Am J Med Genet Neuropsychiatr Genet 2013; 162B: 327-366.

166. Rimland B. The Autism epidemic, vaccinations and mercury. J Nut Environ Med 2000; 10: 261-266.

167. Downing D. Mercury again. J Nut Environ Med 2000; 10: 267-269.

168. Herbert MR. Contributions of the environment and environmentally vulnerable physiology to autism spectrum disorders. Curr Opin Neurol 2010; 23: 103-110.

169. Bransfield RC, Wulfman JS, Harvey WT, Usman AI. The association between tickbourne infections, Lyme borreliosis and autism spectrum disorders. Med Hypotheses 2008; 70: 967-974.

170.Zahir FR, Brown CJ. Epigenetic impacts on neurodevelopment: pathophysiological mechanisms and genetic modes of action. Pediatr Res 2011; 69: 92R-100R.

171. Gadad BS, Hewitson L, Young KA, German DC. Neuropathology and animal models of autism: genetic and environmental factors. Autism Res Treat 2013; 2013: 731935 [Epub Sept 16, 2013].

172. Takahashi H, Arai S, Tanaka-Taya K, et al. Autism and infection/immunization episodes in Japan. Jap J Infect Dis 2001; 54: 78-79

173. Libbey JE, Sweeten TL, McMahon WM, et al. Autistic disorder and viral infections. J Neurovirol 2005; 11: 1-10.

174. Bransfield RC, Kuhn M. Autism and Lyme disease. JAMA 2013; 310: 856-857.

175. Thornton D. A survey of Mycoplasma detection in veterinary vaccines. Vaccine 1986; 4: 237-240.

176. Nicolson GL, Nicolson NL. Diagnosis and treatment of mycoplasmal infections in Persian Gulf War Illness-CFIDS patients. Intern J Occupat Med Immunol Tox 1996; 5: 69-78.

177. Nicolson GL, Nasralla M, Nicolson NL, Haier J. High prevalence of mycoplasmal infections in symptomatic (Chronic Fatigue Syndrome) family members of mycoplasma-positive Gulf War Illness patients. J Chronic Fatigue Syndr 2003; 11(2): 21-36.

178. Nicolson GL, Berns P, Gan R, Haier J. Chronic mycoplasmal infections in Gulf War veterans' children and autism patients. Med Veritas 2005; 2: 383-387.

179. Bransfield RC, Wulfman JS, Harvey WT, Usman AI. The association between tickborne infections, Lyme borreliosis and autism spectrum disorders. Med Hypotheses 2008; 70: 967-974.

180. Frye RE, Rossignol DA. Mitochondrial dysfunction can connect the diverse medical symptoms associated with autism spectrum disorders. Pediatr Res 2011; 59: 41R-47R. 
181. Rossignol DA, Frye RE. Mitochondrial dysfunction in autism spectrum disorders: a systematic review and meta-anlaysis. Mol Psychiatry 2012; 17: 290-314.

182. Rossignol DA, Frye RE. A review of research trends in physiological abnormalities in autism spectrum disorders: immune dysregulation, inflammation, oxidative stress, mitochondrial dysfunction and environmental toxicant exposures. Mol Psychiatry 2012; 17: 389-401.

183. Palmieri L, Persico AM. Mitochondrial dysfunction in autism spectrum disorders: cause or effect? Biochim Biophys Acta 2010; 1797: 1130-1137.

184. McDonald E, David AS, Pelosi AJ, Mann AH. Chronic fatigue in primary care attendees. Psycholog Med 1993; 23: 987-998.

185. Morrison JD. Fatigue as a presenting complaint in family practice. J Family Pract 1980; 10: 795-801.

185. Kroenke K, Wood DR, Mangelsdorff AD, Meier NJ, Powell JB. Chronic fatigue in primary care. Prevalence, patient characteristics, and outcome. JAMA 1988; 260: 929-934.

187. Fukuda K, Strauss SE, Hickie I, Sharpe MC, Dobbines JG, Komaroff A. The Chronic Fatigue Syndrome, a comprehensive approach to its definition and study. Ann Internal Med 1994; 121: 953-959.

188. Crothers BM, Jain AK, De Meirleir KL, Peterson DL, Klimas NG, Lerner AM, Bested AC, Flor-Henry P, Joshi P, Powles ACP, Sherkey JA, van de Sande MI. Myalgic encephalomyelitis/chronic fatigue syndrome: clinical working case definition, diagnostic and treatment protocols. J Chronic Fatigue Syndr 2003; 11(1): 7-116.

189. Fletcher MA, Maher KJ, Klimas NG. Natural Killer cell function in chronic fatigue syndrome. Clin Appl Immunol Rev 2002; 2: 129-139.

190. Nijs J, Fremont M. Intercellular immune dysfunction in myalgic encephalomyelitis/chronic fatigue syndrome: state of the art and therapeutic implications. Expert Opin Ther Targets 2008; 12: 281-289.

191. Tanriverdi F, Karaca Z, Unluhizarci K, Kelestimur F. The hypothalamo-pituitaryadrenal axis in chronic fatigue syndrome and fibromyalgia syndrome. Stress $2007 ; 10$ : 13-25.

192. Patarca R. Cytokines and chronic fatigue syndrome. Ann New York Acad Sci 2001; 933: $185-200$.

193. Silverman MN, Heim CM, Nater UM, Marques AH, Sternberg EM. Neuroendocrine and immune contributors to fatigue. PMR 2010; 2: 338-346.

194. Lorusso L, Mikhaylova SV, Capelli E, Ferrari D, Ngonga GK, Ricevuti G. Immunological aspects of chronic fatigue syndrome. Autoimmun Rev 2009; 8: 287291.

195. Klimas NG, Broderick G, Fletcher MA. Biomarkers for chronic fatigue. Brain Behav Immun 2012; 26: 1202-1210.

196. Nicolson GL, Nasralla M, Franco AR, Nicolson NL, Erwin R, Ngwenya R, Berns PA. Diagnosis and integrative treatment of intracellular bacterial infections in chronic fatigue 
and fibromyalgia syndromes, Gulf War illness, rheumatoid arthritis and other chronic illnesses. Clin Pract Alt Med 2000; 1(2): 92-102.

197. Nicolson, G.L., Nasralla, M., Gan, R., Haier, J. and De Meirleir, K. Evidence for bacterial (Mycoplasma, Chlamydia) and viral (HHV-6) co-infections in chronic fatigue syndrome patients. J Chronic Fatigue Syndr 2003; 11(2): 7-20.

198. Zhang L, Gough J, Christmas D, Mattey DL, Richards SC, Main J, Enlander D, Honeybourne D, Ayres JG, Nutt DJ, Kerr JR. Microbial infections in eight genomic subtypes of chronic fatigue syndrome/myalgic encepthalomyelitis. J Clin Pathol 2010; 63: 156-164.

199. Komaroff AL, Cho TA. Role of infection and neurologic dysfunction in chronic fatgue syndrome. Semin Neurol 2011; 31: 325-337.

200. Vojdani A, Choppa PC, Tagle C, Andrin R, Samimi B, Lapp CE. Detection of Mycoplasma genus and Mycoplasma fermentans by PCR in patients with Chronic Fatigue Syndrome. FEMS Immunol Med Microbiol 1998; 22: 355-365.

201. Nicolson GL, Gan R, Haier J. Multiple co-infections (Mycoplasma, Chlamydia, human herpesvirus-6) in blood of chronic fatigue syndrome patients: association with signs and symptoms. APMIS 2003; 111: 557-566.

202. Vernon SD, Shukia SK, Reeves WC. Absence of Mycoplasma species DNA in chronic fatigue syndrome. J Med Microbiol 2003; 52: 1027-1028.

203. Nijs J, Nicolson GL, De Becker P, Coomans D, De Meirleir K. High prevalence of mycoplasmal infections among European Chronic Fatigue Syndrome patients. Examination of four Mycoplasma species in Chronic Fatigue Syndrome patients. FEMS Immunol Med Microbiol 2002; 34: 209-214.

204. Nicolson GL, Nicolson NL, Haier J. Chronic Fatigue Syndrome patients subsequently diagnosed with Lyme Disease Borrelia burgdorferi: evidence for Mycoplasma species co-infections. J Chronic Fatigue Syndr 2008; 15(4): 5-17.

205. Chia JKS, Chia LY. Chronic Chlamydia pneumoniae infection: a treatable cause of Chronic Fatigue Syndrome. Clin Infect Dis 1999; 29: 452-453.

206. Beqaj SH, Lerner AM, Fitzheerald JT. Immunossay with cytomegalovirus early antigens from gene products p52 and CM2 (UL44 and UL57) detects active infection in patients with chronic fatigue syndrome. J Clin Pathol 2008; 61: 623-526.

207. Seishima M, Mizutani Y, Shibuya Y, Arakawa C. Chronic fatigue syndrome after human parvovirus B19 infection without persistent viremia. Dermatol 2008; 216: 341346.

208. Wagner M, Krueger GRF, Ablashi DV, Whitman JE. Chronic fatigue syndrome (CFS): a critical evaluation of testing for active human herpesvirus-6 (HHV-6) infection: a review of data on 107 cases. J Chronic Fatigue Syndr 1996; 5: 3-16.

209. Delviks-Frankenberry K, Cingöz O, Coffin JM, Pathak VK. Recombinant orgin, contamination and de-discovery of XMRV. Curr Opin Virol 2012; 2: 499-507.

210. Myhill S, Booth NE, McLaren-Howard J. Chronic fatigue syndrome and mitochondrial dysfunction. Intern J Clin Exp Med 2009; 2(1): 1-16. 
211. Booth ME, Myhill S, McLaren-Howard J. Mitochonrial dysfunction and the pathophysiology of myalgic ecephalomyelitis/chronic fatigue syndrome (ME/CFS). Intern J Clin Exp Med 2012; 5: 208-220.

212. Agadjanyan M, Vasilevko V, Ghochikyan A, Berns P, Kesslak P, Settineri R, Nicolson GL. Nutritional supplement (NTFactor) restores mitochondrial function and reduces moderately severe fatigue in aged subjects. J Chronic Fatigue Syndr 2003; 11(3): 2326.

213. Myhill S, Booth NE, McLaren-Howard J. Targeting mitochondrial dysfunction in the treatment of myalgic encepthalomyelitis/chronic fatigue syndrome (ME/CFS) - a clinical audit. Intern J Clin Exp Med 2013; 6(1): 1-15.

214. Rehm SE, Koroschetz J, Gockel U, Brosz M, Freynhagen R, Tölle TR, Baron R. A cross-sectional survey of 3035 patients with fibromyalgia: subgroups of patients with typical comorbidities and sensory symptom profiles. Rheumatol 2010; 49: 1146-1152.

215. Breeding PC, Russell NC, Nicolson GL. An integrative model of chronically activated immune-hormonal pathways important in the generation of fibromyalgia. Brit $\mathbf{J}$ Med Practit 2012; 5(3): a524-a534.

216. Arnold LM, Hudson JI, Hess EV, Ware AE, Fritz DA, Auchenbach MD, Starck LO, Keck PE Jr. Family study of fibromyalgia. Arthritis Rheum 2004; 50: 944-952.

217. Neumann L, Buskila D. Epidemiology of fibromyalgia. Curr Pain Headache Rep 2003; 7(5): 362-368.

218. Bazzichi L, Rossi A, Giuliano T, De Feo F, Giacomelli C, Consensi A, Ciapparelli A, Consoli G, Dellosso L, Bombardieri S. Association between thyroid autoimmunity and fibromyalgic disease severity. Clin Rheumatol 2007; 26: 2115-2120.

219. Ribeiro LS, Proietti FA. Interrelations between fibromyalgia, thyroid autoantibodies, and depression. J Rheumatol 2004; 31: 2036-2040.

220. Klein R, Bansch M, Berg PA. Clinical relevance of antibodies against serotonin and gangliosides in patients with primary fibromyalgia syndrome. Psychoneuroendocrinol 1992; 17(6): 593-598.

221. Cordero MD, de Miguel M, Carmona-López I, Bonal P, Campa F, Moreno-Fernández AM. Oxidative stress and mitochondrial dysfunction in fibromyalgia. Neuro Endocrinol Lett 2010; 31: 169-173.

222. Codero MD, De Miguel M, Moreno Fernández AM, Carmona López IM, Carrido Maraver J, Cotán D, Gómez Izquierdo L, Bonal P, Campa F, Bullon P, Navas P, Sánchez Alcázar JA. Mitochondrial dysfunction and mitophagy activation in blood mononuclear cells of fibromyalgia patients: implications in the pathogenesis of the disease. Arthritis Res Ther 2010; 12(1): R17 [Jan 28, 2010 Epub].

223. Castro-Marrero J, Cordero MD, Sáez-Francas N, Jimenez-Gutierrez C, AguilarMontilla FJ, Aliste L, Alegre-Martin J. Could mitochondrial dysfunction be a differentiating marker between chronic fatigue syndrome and fibromyalgia? Antioxid Redox Signal 2013; May 29 [Epub ahead of print].

224. Twig G, Shirihi OS. The interplay between mitochondrial dynamics and mitophagy. Antiox Redox Signal 2011; 14: 1939-1951. 
225. Rich PR, Marechal A. The mitochondrial respiratory chain. Essays Biochem 2010; 47: $1-23$.

226. Nicholls DG. Mitochondrial ion circuits. Essays Biochem 2010; 47: 25-35.

227. Richter C, Par JW, Ames B. Normal oxidative damage to mitochondrial and nuclear DNA is extensive. Proc Nat Acad Sci USA 1998; 85: 6465-6467.

228. Paradies G, Petrosillo G, Paradies V, Ruggiero FM. Mitochondrial dysfunction in brain aging: role of oxidative stress and cardiolipin. Neurochem Intern 2011; 58: 447-457.

229. Stadtman E. Introduction to serial reviews on oxidatively modified proteins in aging and disease. Free Radical Biol Med 2002; 32: 789.

230. Duchen MR, Szabadkai G. Roles of mitochondria in human disease. Essays Biochem 2010; 47: 115-137.

231. Divakaruni AS, Brand MD. The regulation and physiology of mitochondrial proton leak. Physiology 2011; 26: 192-205.

232. Chicco AJ, Sparagna GC. Role of cardiolipin alterations in mitochondrial dysfunction and disease. Am J Physiol Cell Physiol 2007; 292: C33-C44.

233. Houtkooper RH, Vaz FM. Cardiolipin, the heart of mitochondrial mechanisms. Cell Molec Life Sci 2008; 65: 2493-2506.

234. Barber DA, Harris SR. Oxygen free radicals and antioxidants: a review. Am Pharmacol 1994; 34: 26-35

235. Sun Y. Free radicals, antioxidant enzymes and carcinogenesis. Free Radical Biol Med 1990; 8: 583-599.

236. Fridovich I. Superoxide radical and superoxide dismutases. Annu Rev Biochem 1995; 64: 97-112.

237. Marí M, Morales A, Colell A, Garcia-Ruiz C, Kaplowitz N, Fernández-Checa JC. Mitochondrial glutathione: features, regulation and role in disease. Biochim Biophys Acta 2013; 1830: 3317-3328.

238. Diplock AT, Charleux JL, Crozier-Willi G, Kok FJ, Rice-Evans C, Roberfroid M, Stahl W, Viña-Ribes J. Functional food science and defence against reactive oxidation species. Br J Nutr 1998; 80(Suppl 1): S77-S112.

239. Albarracin SL, Stab B, Casas Z, Sutachan JJ, Samudio I, Gonzalez J, Gonzalo L, Capani F, Morales L, Bareto GE. Effects of natural antioxidants in neurodegenerative disease. Nutr Neurosci 2012; 15: 1-9.

240. Maarchal J, Pifferi F, Aujard F. Reservatrol in mammals: effects on aging biomarkers, age-related diseases and life span. Ann N Y Acad Sci 2013; 1290: 67-73.

241. Obrenovich ME, Li Y, Parvathaneni K, Yendluri BB, Palacios HH, Leszek J, Aliev G. Antioxidants in health, disease and aging. CNS Neurol Discord Drug Targets 2011; 10: 192-207.

242. DiMauro S, Rustin P. A critical approach to the therapy of mitochondrial respiratory chain and oxidative phosphorylation diseases. Biochim Biophys Acta 2009; 1792: 1159-1167.

243. Kerr DS. Treatment of mitochondrial electron transport chain disorders: a review of clinical trials over the past decade. Mol Genetics Metabol 2010; 99: 246-255. 
244. Nicolson GL, Ash ME. Lipid Replacement Therapy: a natural medicine approach to replacing damaged phospholipids in cellular membranes and organelles and restoring function. Biochim Biophys Acta 2013; 1838: in press.

245. Chambers D, Bagnall A-M, Hempel S, Forbes C. Interventions for the treatment, management and rehabilitation of patients with chronic fatigue syndrome/myalgic encepthalomyelitis: an updated systematic review. J Royal Soc Med 2006; 99: 506520.

246. Reuter SE, Evans AM. Carnitine and acylcarnitines: pharmacokinetic, pharmacological and clinical aspects. Clin Pharmacokinet 2012; 51: 553-572.

247. Marcovina SM, Sirtori C, Peracino A, Gheorghiade M, Borum P, Remuzzi G, Ardehali H. Translating the basic knowledge of mitochondrial functions to metabolic therapy: role of L-carnitine. Translat Res 2012; Nov 5, pii: S1931-5244(12)00367-2. doi: 10.1016/j.trs12012.10.006.

248. Koves TR, Ussher JR, Noland RC, Slentz D, Mosedale M, Ilkayeva O, Bain J, Stevens R, Dyck JR, Newgard CB, Lopaschuk GD, Muoio DM. Mitochondrial overload and incomplete fatty acid oxidation contribute to skeletal muscle insulin resistance. Cell Metab 2008; 7: 45-56.

249. Shah SH, Hauser ER, Bain JR, Muehlbauer MJ, Haynes C, Stevens RD, Wenner BR, Dowdy ZE, Granger CB, Ginsburg GS, Newgard CB, Kraus WE. High heritability of metabolomic profiles in families burdened with premature cardiovascular disease. Mol Syst Biol 2009; 5: 258. doi:10.1038/msb.2009.11.

250. Spriet LL, Perrry CGR, Talanian JL. Legal pre-event nutritional supplements to assist energy metabolism. Essays Biochem 2008; 44: 27-43.

251. Brass EP. Supplemental carnitine and exercise. Am J Clin Nutr 2000; 72; 618S-623S.

252. Yoshida K, Hirokawa J, Tagami S, Kawakami Y, Urata Y, Kondo T. Weakened cellular scavenging activity against oxidative stress in diabetes mellitus: regulation of glutathione synthesis and efflux. Diabetologia 1995; 38: 201-210.

253. Anand I, Chandrashekhan Y, De Giuli F, Pasini E, Mazzoletti A, Confortini R, Ferrari R. Acute and chronic effects of propionyl-L-carnitine on the hemodynamics, exercise capacity and hormones in patients with congestive heart failure. Cardiovasc Drugs Ther 1998; 12: 291-299.

254. Acetyl-L-Carnitine Monograph. Altern Med Rev 2010; 15(1): 76-83.

255. Malaguarnera M, Cammalleri L, Gargante MP, Vacante M, Colonna V, Motta M. Lcarnitine treatment reduces severity of physicial and mental fatigue and increases cognitive functions in centenarians: a randomized and controlled clinical trial. Am J Clin Nutr 2007; 86: 1738-1744.

256. Smith AR, Shenvi SV, Widlansky M, Suh JH, Hagen TM. Lipoic acid as a potential therapy for chronic diseases associated with oxidative stress. Curr Medicinal Chem 2004; 11: 1135-1146.

257. Marczurek A, Hager K, Kenklies M, Sharman M, Martins R, Engel J, Carlson DA, Munch G. Lipoic acid as an anti-inflammatory and neuroprotective treatment for Alzheimer's disease. Adv Drug Deliv Rev 2008; 60: 1463-1470. 
258. Shay KP, Moreau RF, Smith EJ, Smith AR, Hagen TM. Alpha-lipoic acid as a dietary supplement: molecular mechanisms and therapeutic potential. Biochim Biophys Acta 2009; 1790: 1149-1160.

259. Estrada DE, Ewart HS, Tsakiridis T, Volchuk A, ramtal T, Tritschler H, Klip A. Stimulation by alpha-lipoic acid of glucose transport activity in skeletal muscle of lean and obese Zucker rats. Life Sci 1997; 61: 805-812.

260. Gudz TI, Tserng KY, Hoppel CL. Direct inhibition of mitochondrial respiratory chain complex III by cell-permeable ceramide. J Biol Chem 1997; 272: 24154-24158.

261. Di Paola M, Cocco T, Lorusso M. Ceramide interaction with the respiratory chain of heart mitochondria. Biochem. 2000; 39: 6660-6668.

262. Monette JS, Gomez LA, Moreau RF, Dunn KC, Butler JA, Finlay LA, Michels AJ, Shay KP, Smith EJ, Hagen TM. (R)- $\square \square$-Lipoic acid treatment restores ceramide balance in aging rat cardiac muscle. Pharmacol Res 2011; 63: 23-29.

263.Ziegler D, Nowak H, Kempler P, Vargha P, Low PA. Treatment of symptomatic diabetic polyneuropathy with the antioxidant alpha-lipoic acid: a meta-analysis. Diabet Med 2004; 21: 114-121.

264.Ziegler D, Low PA, Litchy WJ, Boulton AJM, Vink AI, Freeman R, Samigullin R, Tritschler H, Munzel U, Maus, J, Schute K, Dyck PJ. Efficacy and safety of antioxidant treatment with $\square \square$-Lipoic acid over 4 years in diabetic polyneuropathy. Diabetes Care 2011; 34: 2054-2060.

265. Goraca A, Huk-Kolega H, Piechota A, Kleniewska P, Ciejka E, Skibska B. Lipoic acid - biological activity and therapeutic potential. Pharmacol Rep 2011; 63: 849-858.

266. Head E, Nukala VN, Fenoglio KA, Muggenburg BA, Cotman CW, Sullivan PG. Effects of age dietary and behavioral enrichment on brain mitochondria in a canine model of human aging. Exp Neurol 2009; 220: 171-176.

267. Littarru GP, Tiano L. Clinical aspects of coenzyme Q10: an update. Nutr 2010; 26 : 250-254.

268. Groneberg DA, Kindermann B, Althammer M, Klapper M, Vormann J, Littarru GP, Doring F. Coenzyme $\mathrm{Q}_{10}$ affects expression of genes involved in cell signaling, metabolism and transport in CaCo-2 cells. Intern J Biochem Cell Biol 2005; 37: 12081218.

269. Orsucci D, Mancuso M, Ienco EC, LoGerfo A, Siciliano G. Targeting mitochondrial dysfunction and neurodegeneration by means of coenzyme Q10 and its analogues. Curr Medicinal Chem 2011; 18: 4053-4064.

270. Rosenfeldt F, Hilton D, Pepe S, Krum H. Systematic review of effect of coenzyme Q10 in physical exercise, hypertension and heart failure. Biofactors 2003; 18: 91-100.

271. Mizuno K, Tanaka M, Nozaki S, Mizuma H, Ataka S, Tahara T, Sugino T, Shirai T, Kajimoto Y, Kuratsune H, Kajimoto O, Watanabe Y. Antifatigue effects of coenzyme Q10 during physical fatigue. Nutr 2008; 24: 293-299.

272. Li G, Jack CR, Yang XF, Yang ES. Diet supplement CoQ10 delays brain atrohy in aged transgenic mice with mutations in the amyloid precursor protein: an in vivo volume MRI study. Biofactors 2008; 32: 169-178 
273. Yang X, Dai G, Li G, Yang ES. Coenzyme Q10 reduces beta-amyloid plaque in an APP/PSI transgenic mouse model of Alzheimer's disease. J Mol Neurosci 2010; 41: 110-113.

273. Galasko DR, Peskind E, Clark CM, Quinn JF, Ringman JM, Jicha GA, Cotman C, Cotrell B, Montine TJ, Thomas RG, Aisen P. Antioxidants for Alzheimer's disease: a randomized clinical trial with cerebrospinal fluid biomarker measures. Arch Neurol 2012; 69: 836-841.

274. Isobe C, Abe T, Terayama Y. Levels of reduced and oxidized coenzyme Q10 and 8hydroxy-2'-deoxyguanosine in the cerebrospinal fluid of patients with living Parkinson's disease demonstrates that mitochondrial oxidative damage contributes to the neurodegenerative process. Neurosci Lett 2010; 220: 41-48.

275. Kieburtz K, Huntington Study Group. A randomized, placebo-controlled trial of coenzyme Q10 and remacemide in Huntington's disease. Neurol 2001; 57: 397-404.

276. Thompson KP, Levy G, Buchsbaum R, Shefner J, Krivickas LS, Katz J, Rollins Y, Barohn RJ, Jackson CE, Tiryaki E, Lomen-Hoerth C, Armon C, Tandan R, Rudnicki SA, Rezania K, Sufit R, Pestronk A, Novella SP, Heiman-Patterson T, Kasarskis EJ, Pioro EP, Montes J, Arbing R, Vecchio D, Barsdorf A, Mitsumoto H, Levin B. Phase II trial of CoQ10 for ALS finds insufficient evidence to justify phase III. Ann Neurol 2009; 66: 235-244.

277. Mathews PM, Ford B, Dandurand RJ, Eidelman DH, O'Connor D, Sherwin A, Karpati G, Andermann F, Arnold DL. Coenzyme Q10 with multiple vitamins is generally ineffective in treatment of mitochondrial disease. Neurol 1993; 43: 884-890.

278. Kirkland JB. Niacin status, NAD distribution and ADP-ribose metabolism. Curr Pharmaceut Design 2009; 15(1): 3-11.

279. Penberthy WT. Nicotinamide adenine dinucleotide biology and disease. Curr Pharmaceut Design 2009; 15(1): 1-2.

280. Birkmayer JG. Coenzyme nicotinamide adenine dinucleotide: new therapeutic approach for improving dementia of the Alzheimer type. Ann Clin Lab Sci 1996; 26(1): 1-9.

281. Swerdlow RH. Brain aging, Alzheimer's disease and mitochondria. Biochim Biophys Acta 2011; 1812: 1630-1639.

282. Reddy PH. Mitochondrial medicine for aging and neurodegenerative diseases. Neuromolec Med 2008; 10: 291-315.

283. Victor VM, Apostolova N, Herance R, Hernandez-Mijares A, Rocha M. Oxidative stress and mitochondrial dysfunction in atherosclerosis: mitochondria-targeted antioxidants as potential therapy. Curr Med Chem 2009; 16: 4654-4667.

284. Reddy PH, Reddy TP. Mitochondria as a therapeutic target for aging and neurodegenerative diseases. Curr Alzheimer Res 2011; 8: 393-409.

285. Demarin V, Podobnik SS, Storga-Tomic D, Kay G. Treatment of Alzheimer's disease with stabilized oral nicotinamide adenine dinucleotide: a randomized, double-blind study. Drugs Exp Clin Res 2004; 30(1):27-33.

286. Birkmayer JG, Vrecko C, Volc D, Birkmayer W. Nicotinamide adenine dinucleotidea new therapeutic approach to Parkinson's disease. Comparison of oral and parenteral application. Acta Neurol Scand Suppl 1993; 146: 32-35. 
287. Dizdar N, Kagedal B, Lindvall B. Treatment of Parkinson's disease with NADH. Acta Neurol Scand 1994; 90: 345-347.

288. Forsyth LM, Preuss HG, MacDowell AL, Chiazze L jr, Birkmayer GD, Bellanti JA. Therapeutic effects of oral NADH on the symptoms of patients with chronic fatigue syndrome. Ann Allergy Asthma Immunol 1999; 82: 185-191.

289. Colquhoun D, Senn S. Is NADH effective in the treatment of chronic fatigue syndrome? Ann Allergy Asthma Immunol 2000; 84: 639-640.

290. Santaella ML, Font I, Disdier OM. Comparison of oral nicotinamide adenine dinucleotide (NADH) versus conventional therapy for chronic fatigue syndrome. Puerto Rico Health Sci J 2004; 23: 89-93.

291. Alegre J, Rosés JM, Javierre C, Ruiz-Baqués A, Segundo MJ, de Sevilla TF. Nicotinamide adenine dinucleotide (NADH) in patients with chronic fatigue syndrome. Rev Clin España 2010; 210: 284-288.

292. Ellithorpe RR, Settineri R, Nicolson GL. Reduction of fatigue by use of a dietary supplement containing glycophospholipids. J Am Nutraceut Assoc 2003; 6(1): 23-28.

293. Nicolson GL, Ellithrope R. Lipid replacement and antioxidant nutritional therapy for restoring mitochondrial function and reducing fatigue in chronic fatigue syndrome and other fatiguing illnesses. J Chronic Fatigue Syndr 2006; 13(1): 57-68.

294. Piper BF, Linsey AM, Dodd MJ. Fatigue mechanism in cancer. Oncol Nurs Forum 1987; 14: 17-23.

295. Nicolson GL, Ellithorpe RR, Ayson-Mitchell C, Jacques B, Settineri R. Lipid Replacement Therapy with a glycophospholipid-antioxidant-vitamin formulation significantly reduces fatigue within one week. J Am Nutraceutical Assoc 2010; 13(1): $10-14$.

296. Kucharská J. Vitamins in mitochondrial function, in: Gvozdjáková A, ed. Mitochondrial Medicine, Springer, Netherlands, 2008, pp. 367-384.

297. Ames BN, Atamna H, Killilea DW. Mineral and vitamin deficiencies can accelerate the mitochondrial decay of aging. Mol Aspects Med 2005; 26: 363-378.

298. Scarpelli M, Cotelli MS, Mancuso M, Tomelleri G, Tonin P, Baronchelli C, Vielmi V, Gregorelli V, Todeschini A, Padovani A, Filosto M. Current options in the treatment of mitochondrial diseases. Recent Pat CNS Drug Discov 2010; 5: 203-209.

299. Ames BN. A role for supplements in optimizing health: the metabolic tune-up. Arch Biochem Biophys 2004; 423: 227-234.

300. Sies H, Stahl W, Sundquist AR. Antioxidant functions of vitamins, mitamins E and C, beta-carotene and other carotenoids. Ann N Y Acad Sci 1992; 669: 7-20.

301. Wojcik M, Burzynska-Pedziwiatr I, Wozniak LA. A review of natural and synthetic antioxidants important for health and longevity. Curr Med Chem 2010; 17: 3268-3288.

302. Huskisson E, Maggini S, Ruf M. Energy metabolism and well being. J Intern Med Res 2007; 35: 277-289.

303. Nicolson GL, Settineri R, Ellithorpe E. Lipid Replacement Therapy with a glycophospholipid formulation with NADH and CoQ10 significantly reduces fatigue in intractable chronic fatiguing illnesses and chronic Lyme disease. Intern J Clin Med 2012; 3(3): 163-170. 
304. Perez-Pinzon MA, Stetler RA, Fiskum G. Novel mitochondrial targets for neuroprotection. J Cerebral Blood Flow Met 2012; 32: 1362-1376.

305. Galluzzi L, Kepp O, Kroemer G. Mitochondria: master regulators of danger signaling. Nat Rev Cell Mol Biol 2012; 13: 780-788.

306. Lartigue L, Faustin B. Mitochondria: metabolic regulators of innate immune responses to pathogens and cell stress. Intern J Biochem Cell Biol 2013; 45: 2052-2056.

307. Arnoult D, Soares F, Tattoli I, Girardin SE. Mitochondria in innate immunity. EMBO Rep 2011; 901-910.

308. Yuk J-M, Yoshimori T, Jo E-K, Autophagy and bacterial infectious disease. Exp Mol Med 2012; 44: 99-108.

309. Campoy E, Colombo MI. Autophagy in intracellular bacterial infection. Biochim Biophys Acta 2009; 1793: 1465-1477.

310. Orvedalh A, Levine B. Eating the enemy within: autophagy in infectious diseases. Cell Death Differ 2009; 16: 57-69.

311. Jo EK, Yang CS, Choi CH, Harding CV. Intracellular signaling cascades regulating innate immune responses to Mycobacteria: branchig out form Toll-like receptors. Cell Microbiol 2007; 9: 1087-1098.

312. Brodsky IE, Medzhitov R. Targeting of immune signaling networks by bacterial pathogens. Nat Cell Biol 2009; 11: 521-526.

313. Schroder K, J. Tschopp J. The inflammasomes. Cell 2010; 140: 821-832.

314. Krysko DV, Agostinis P, Krysko O, Garg AD, Bachert C, Lambrecht BN, Vandenabeele P. Emerging role of damage-associated molecular patterns derived from mitochondria in inflammation. Trends Immunol 2011; 32: 157-164.

315. Krysko DV, Agostinis P, Krysko O, Garg AD, Bachert C, Lambrecht BN, Vandenabeele P. Emerging role of damage-associated molecular patterns derived from mitochondria in inflammation. Trends Immunol 2011; 32: 157-164.

316. Kryso DV, Vandenabeele P. Clearance of dead cells: mechanisms, immune responses and implication in the development of disease. Apoptosis 2010; 15: 995-997.

317. Kroemer G, Galluzzi L, Brenner C. Mitochondrial membrane permeabilization in cell death. Physiol Rev 2007; 87: 99-163.

318. Tait SW, Green DR. Mitochondria and cell death: outer membrane permebilization and beyond. Nat Rev Mol Cell Biol 2010; 11: 621-632.

319. Ellithorpe RA, Settineri R, Jacques B, Nicolson GL. Lipid Replacement Therapy functional food with NT Factor for reducing weight, girth, body mass, appetite, cravings for foods and fatigue while improving blood lipid profiles. Funct Food Health Dis 2012; 2(1): 11-24. 